\section{rev Psi}

Revista de Psicología (UNLP)

https://revistas.unlp.edu.ar/revpsi

\title{
Perspectivas neurobiológicas para explicar el autismo: una revisión sistemática de literatura
}

\author{
Martín Sosa $^{1} \quad$ Nicolás Alessandroni ${ }^{2} \quad$ María Cristina Piro $^{1}$ \\ Correspondencia \\ martinsosa047@yahoo.com.ar \\ Filiaciones institucionales \\ ${ }^{1}$ Laboratorio de Investigaciones en Psicoanálisis y ${ }^{2}$ Departamento Interfacultativo de Psicología \\ Psicopatología (LIPPSI), Facultad de Psicología, Evolutiva y de la Educación, Facultad de Psico- \\ Universidad Nacional de La Plata (UNLP) logía, Universidad Autónoma de Madrid (UAM) \\ (Argentina) \\ (España)
}

\section{Resumen}

En este artículo se abordan las perspectivas neurobiológicas para explicar el autismo a partir de una revisión sistemática de literatura académica. Partimos de considerar a la neurobiología como un campo complejo que estudia los aspectos anátomo-fisiológicos del sistema nervioso central. En vinculación con el autismo, reconocemos dentro de este campo cuatro perspectivas principales: i) la perspectiva neuroanatómica, ii) la perspectiva neurosocial, iii) la perspectiva genética y iv) la perspectiva neuroquímica. Luego de desarrollar cada una, analizamos posibles compatibilidades, yuxtaposiciones y contraposiciones entre ellas.

\section{Palabras clave}

neurobiología | autismo | psicopatología infanto-juvenil | revisión sistemática

\section{Cómo citar}

Sosa, M., Alessandroni, N. y Piro, M.C. (2017). Perspectivas neurobiológicas para explicar el autismo: una revisión sistemática de literatura. Revista de Psicología, 16, 6696. doi: $10.24215 / 2422572 \mathrm{Xe} 006$
DOI

10.24215/2422572Xe006

\section{Recibido}

15 ago. 2017

Aceptado

29 nov. 2017

Publicado

22 dic. 2017

Editor

Nicolás Alessandroni | Facultad de Psicología, Universidad Autónoma de Madrid (España)
ISSN

2422-572X

Licencia

(c) Copyright: Sosa, M. et al. Este trabajo se distribuye bajo una licencia de Cultura Libre CC-BY 4.0

Entidad editora

RevPsi es una publicación de la

Facultad de Psicología (Universidad

Nacional de La Plata, Argentina)

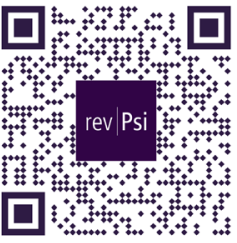

ACCESO ABIERTO DIAMANTE 


\section{Perspectivas neurobiológicas para explicar o autismo: uma revisão sistemática da literatura}

\section{Resumo}

Neste artigo, as perspectivas neurobiológicas para explicar o autismo são abordadas a partir de uma revisão sistemática da literatura acadêmica. Começamos por considerar a neurobiologia como um campo complexo que estuda os aspectos anatomo-fisiológicos do sistema nervoso central. Em conexão com o autismo, reconhecemos quatro perspectivas principais dentro deste campo: i) a perspectiva neuroanatômica, ii) a perspectiva neurocial, iii) a perspectiva genética e iv) a perspectiva neuroquímica. Após o desenvolvimento de cada um, analisamos possíveis compatibilidades, justaposições e oposições entre elas.

\section{Palavras-chave}

neurobiologia | autismo | psicopatologia infantil-juvenil | revisão sistemática

\section{Neurobiological perspectives to explain autism: a systematic literature review}

\section{Abstract}

In this article, we approach the neurobiological perspectives to explain autism by means of a systematic review of academic literature. We start by considering neurobiology as a complex field that studies the anatomo-physiological aspects of the central nervous system. In connection with autism, we recognize four main perspectives within this field: i) the neuroanatomical perspective, ii) the neurosocial perspective, iii) the genetic perspective and iv) the neurochemical perspective. After developing the main ideas of each perspective, we analyze possible compatibilities, juxtapositions and oppositions between them.

\section{Keywords}

neurobiology | autism | child \& adolescent psychopathology | systematic review 


\section{Aspectos destacados del trabajo}

- Delimitamos cuatro grandes perspectivas que se enmarcan dentro del campo de la neurobiología del autismo.

- Analizamos metateóricamente la perspectiva neuroanatómica, la perspectiva neurosocial, la perspectiva genética y la perspectiva neuroquímica.

- La tarea que realizamos constituye un emprendimiento epistemológicamente necesario aún no sistematizado.

- El conocimiento de diversas filiaciones teóricas podría optimizar el abordaje clínico con sujetos con autismo.

El trastorno del espectro autista (TEA) es comúnmente definido como un trastorno del neurodesarrollo que incluye desórdenes en la esfera afectiva y comunicacional (Lai, Lombardo y Baron-Cohen, 2014). Desde que Leo Kanner (1943) lo definiera por primera vez en el contexto de la psiquiatría clásica, se lo ha vinculado con alteraciones tempranas en el contacto con los otros, con trastornos en la comunicación social, en el lenguaje, y en intereses y comportamientos restringidos y estereotipados.

Según Rivière (2001), en los años sesenta se consolida un fuerte corpus científico en relación al autismo y su etiología que lleva a abandonar la hipótesis de la culpabilidad parental y a hallar los primeros indicios claros de asociación de esta patología con trastornos neurobiológicos. Sin embargo, al hacer mención a estos trastornos, diferentes autores se refieren a aportes provenientes de perspectivas muy diversas (genéticas, neuroquímicas, sociales, neuroanatómicas y neurocognitivas, entre otras) de modo indistinto, sin ponderar de modo adecuado el rol, el alcance y las limitaciones de cada una de ellas dentro del campo más amplio de la neurobiología del autismo (Minshew y Payton, 1988; Rapin y Katzman, 1998; Bauman y Kemper, 2005, DiCicco-Bloom et al., 2006; Minshew y Williams, 2007; Lai et al., 2014; Cadaveira y Waisburg, 2014; Martins, 2017). Por otra parte, no se han encontrado publicaciones que se planteen la tarea de analizar metaconceptualmente a la neurobiología del autismo y a las perspectivas que ella comprende. Esta tarea constituye, entonces, un emprendimiento epistemológicamente necesario aún no realizado (Morant, Mulas y Hernández, 2001; Mulas et al., 2005; González y Menchaca, 2007; Acosta, Guzman, Sesarini, Pallia y Quiroz, 2016). El propósito de este trabajo es conceptualizar, sistematizar y analizar críticamente el campo de la neurobiología del autismo, es decir, la rama de la neurobiología que se ocupa de estudiar los aspectos estructurales y funcionales singulares del sistema nervioso central en sujetos con autismo.

Destacamos que, particularmente en los últimos 15 años, el número de investigaciones cuyo tema central es el autismo ha crecido de modo exponencial. Lai et al. (2014), por ejemplo, estiman que entre 2010 y 2012 se han publicado tres veces más artículos 
que en toda la historia previa de investigación sobre la temática, y que dicho interés académico acompaña el creciente número de casos de autismo diagnosticados en instituciones de salud. En Estados Unidos, por ejemplo, en el año 2000, 1 de cada 150 niños era diagnosticado con autismo. En 2012, la cifra asciende a 1 de cada 68 infantes, y se agregan otros estadísticos que se consideran de importancia, como ser que el $46 \%$ de los niños diagnosticados tiene probabilidades de convertirse en un sujeto con una inteligencia superior a la media, y que la variable independiente "género" resulta fundamental, dado que existen cinco veces más casos de autismo en varones que en mujeres (CDC, 2014).

El autismo se ha convertido en un campo de disputas académicas donde confluyen aportes provenientes de los discursos de la medicina, la psiquiatría, las neurociencias, la psicología (desde sus diferentes paradigmas), el psicoanálisis, y la pedagogía, entre otros (Piro, 2015).

Es este contexto el que dota de sentido a la tarea de considerar si los diferentes discursos pueden o no complementarse, enriquecerse, yuxtaponerse, o incluso enfrentarse (Kaulino y Stecher, 2008), poniendo en tensión sus núcleos duros. Veremos que las diversas perspectivas que se incluyen al interior de la neurobiología del autismo exploran no sólo cuestiones relativas a su etiología, sino también a técnicas de diagnóstico cada vez más precoces y a escalas neuropsicológicas específicas (Rotta, 2013). Ellas intentan privilegiar mayormente la precocidad del diagnóstico con el objetivo de ofertar tratamientos eficaces y tempranos.

Algunas de las primeras publicaciones sobre neurobiología del autismo corresponden a trabajos de Minshew y Payton (1988) y de Rapin y Katzman (1998), en los que los autores incluyen estudios genéticos, neuroanatómicos y de neuroimagen. Desde esos primeros escritos hasta la actualidad, se han publicado más de 1000 artículos que mencionan las palabras "neurobiología del autismo", siendo el periodo 2014-2017 el que marca una diferencia sustancial en el número de publicaciones (véase Figura 1).

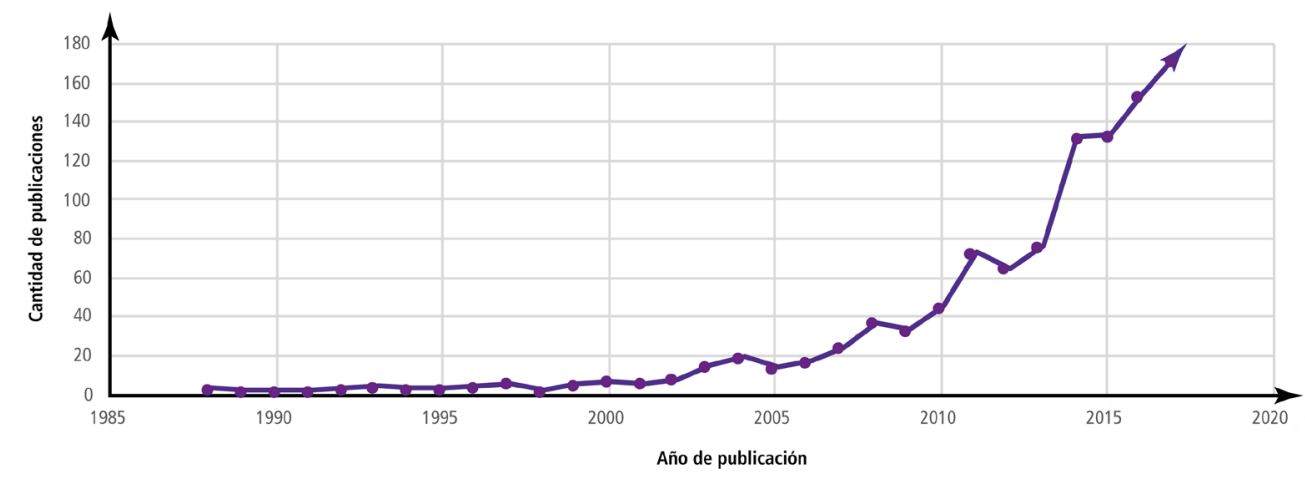

Figura 1. Cantidad de publicaciones por año de publicación 
Mientras que en el periodo 1988-1998 se publicaron 23 artículos con esta temática, en los años 2016-2017, se escribieron 322 trabajos. Estos datos evidencian el sustancial crecimiento de este campo de investigación, y el interés que él ha despertado en la comunidad científica. Por otra parte, esto se ha acompañado de avances tecnológicos para la detección y diagnóstico de este síndrome clínico.

Nuestra revisión pretende evaluar, al interior del campo de la neurobiología del autismo, el grado de inconmensurabilidad de diferentes perspectivas, estableciendo regularidades y tensiones entre ellas, e incluso entre teorías que se enmarcan dentro de una misma perspectiva. Siguiendo la metodología usual para la realización de este tipo de trabajos, hemos encontrado que las investigaciones del campo pueden dividirse en cuatro grupos que describimos y detallamos en las siguientes secciones.

Estimamos que la caracterización de estas perspectivas resulta de importancia fundamental para la psicopatología y para la psicología clínica en virtud del interés y las controversias que el diagnóstico y el tratamiento del autismo tienen en la actualidad. Consideramos, en ese sentido, que conocer sus bases epistemológicas permitiría a los profesionales de la salud mental distinguir con mayor precisión las diversas filiaciones teóricas que confluyen en la labor clínica y el modo preciso en que lo hacen. Esto presenta diferentes consecuencias prácticas para el abordaje del autismo entre las que se cuentan la posibilidad de proponer tratamientos integrales y no reducidos a la propuesta de una única perspectiva, el favorecimiento del trabajo interdisciplinario, la evaluación metateórica de la pertinencia de los criterios de diagnóstico diferencial, y la explicitación del vínculo entre los tratamientos que se llevan a cabo en las prácticas asistenciales con sujetos con autismo y la investigación científica en particular.

\section{Metodología}

Nuestro trabajo constituye una revisión sistemática de literatura académica. Para su elaboración hemos adoptado como marco metodológico las propuestas de la declaración PRISMA para la realización y publicación de revisiones sistemáticas y meta-análisis (Urrútia y Bonfill, 2010). El objetivo general de esta revisión es analizar y comparar un conjunto de estudios teóricos y empíricos vinculados a la neurobiología del autismo, en función de los resultados y las premisas epistemológicas y teóricas que subyacen a ellos.

La búsqueda bibliográfica se realizó consultando las bases de datos más importantes del área (ISI, Web of Science, Scopus, Proquest, ERIH, PubMed, ScienceDirect, PsycINFO, Psicodoc, Dialnet, SciELO, Latindex Catálogo y NBR) a través de las siguientes palabras clave genéricas: neurobiología [neurobiology] y autismo [autism]. Otras palabras clave específicas empleadas para ampliar la profundidad de revisión de cada perspectiva particular se especifican en las secciones subsiguientes.

De acuerdo a nuestro criterio de elegibilidad, seleccionamos artículos, capítulos de libros y libros sobre neurobiología del autismo escritos en los idiomas español e 
inglés, tanto teóricos como empíricos, y publicados entre los años 1998 y 2017. No obstante ello, también se han incluido referencias a escritos anteriores que constituyen antecedentes de relevancia para la temática de la revisión (por ejemplo Kanner, 1943; Asperger, 1944; Folstein y Rutter, 1977). Las características de los estudios empíricos relevados se presentan organizadas en las Tablas 1, 2 y 3.

El análisis realizado permitió trazar una distinción entre diversas perspectivas que podrían agruparse dentro del campo de la neurobiología del autismo: i) la perspectiva neuroanatómica, ii) la perspectiva neurosocial, iii) la perspectiva genética y iv) la perspectiva neuroquímica.

\section{La perspectiva neuroanatómica}

Dentro de ésta se incluyen aquellos trabajos que analizan la estructura y organización del sistema nervioso de los niños autistas, la estructura cerebral, la materia gris y blanca, y sus posibles alteraciones en relación con desarrollos considerados típicos (Amaral, Schumann y Nordahl, 2008) (véase Tabla 1).

Coincidimos con Amaral et al. (2008), quienes distinguen la teoría que estudia el sobrecrecimiento del cerebro de sujetos con TEA durante la vida posnatal de aquella que se enfoca en el estudio del aumento de la sustancia blanca en el cerebro de niños con TEA. Respecto a la primera, existe un gran consenso entre sus investigadores para defenderla. Por ejemplo, Courchesne, Carper y Akshoomoff (2003) demostraron un aumento exagerado y significativo del volumen cerebral de los niños. En su estudio, participaron 48 niños con TEA de 2 a 5 años. Cada uno de ellos había sido evaluado previamente en estudios de resonancia magnética (RM) relacionados con cambios en el cerebro en sujetos con autismo. Utilizaron además, dos bases de datos reconocidas: datos normativos transversales de una encuesta nacional estadounidense y datos longitudinales de crecimiento individual. Los resultados de esta investigación demostraron un aumento anormalmente acelerado en las mediciones de la circunferencia craneal en los niños con TEA. Los autores sostienen que el tamaño de la cabeza aumentó desde el percentil 25 -según los promedios arrojados por la encuesta nacional de niños sanos realizada por CDC (Centers for Disease Control and Prevention)- hasta el percentil 84, entre los 6 y los 14 meses de edad. Lo más llamativo es que este aumento excesivo ocurrió mucho antes de la aparición típica de los síntomas clínicos propios del TEA.

Para Lai et al. (2014), el sobrecrecimiento generalizado del cerebro temprano en los TEA es uno de los rasgos neuroanatómicos más frecuentes de esta patología. Hazlett et al. (2011) suponen que este sobrecrecimiento está asociado a un incremento en la corteza cerebral antes de los dos años de edad. Siguiendo esta hipótesis, realizaron un estudio longitudinal por RM en el que encontraron un agrandamiento cortical generalizado en niños con TEA, con un aumento desproporcionado de la materia blanca del lóbulo temporal. La presencia de un aumento del volumen cortical -no de su grosor- podría estar asociada con el aumento de la superficie cortical, lo cual 


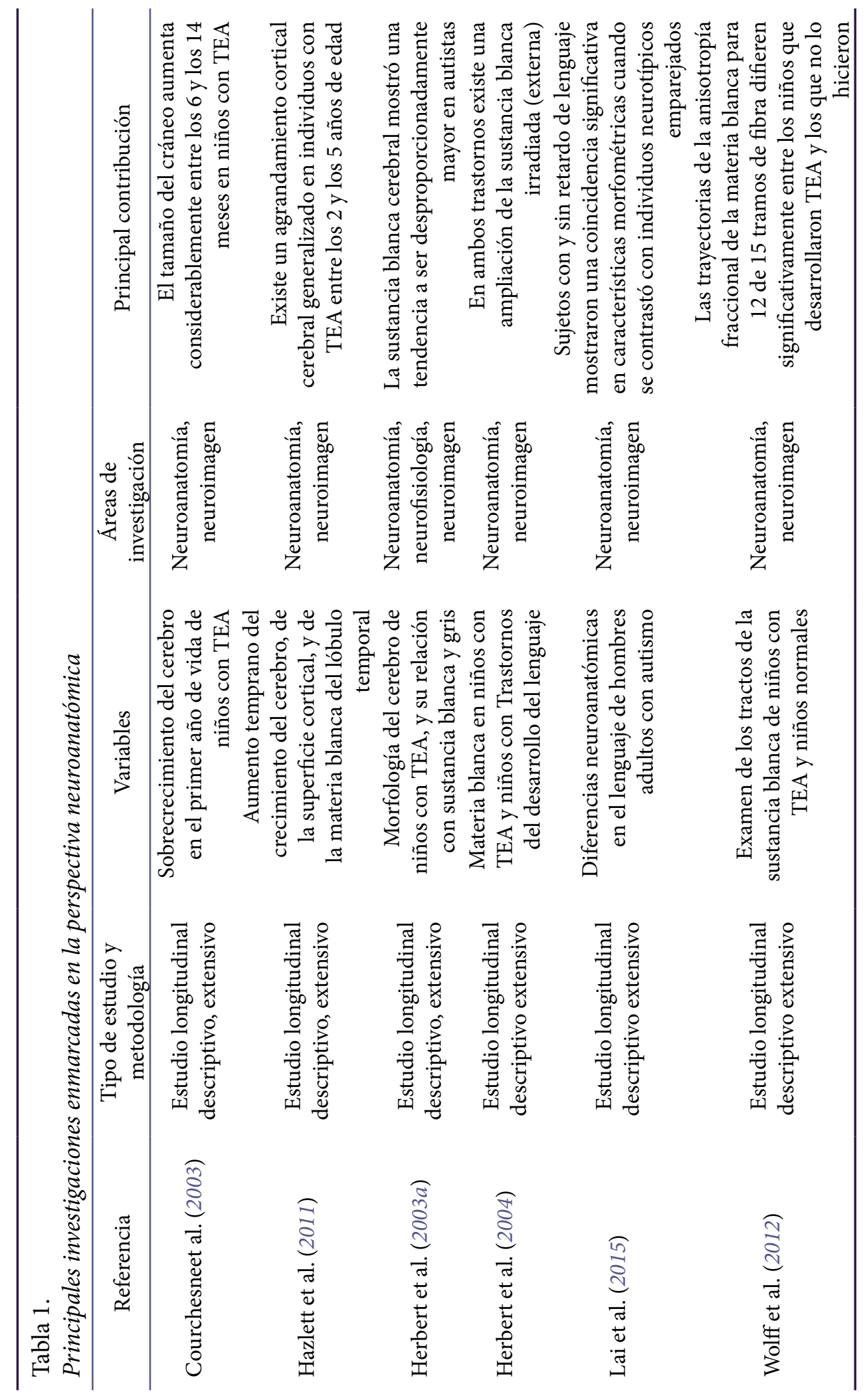


implicaría un conjunto distinto de mecanismos patogénicos.

Apoyando la hipótesis del crecimiento de la corteza, Hutsler y Casanova (2016) sugieren que esta maduración prolongada durante el desarrollo humano ejemplifica cómo la biología y el medio ambiente están inexorablemente entrelazados en la construcción de complejos circuitos neuronales. Estas alteraciones en los circuitos corticales probablemente subyacen al fenotipo conductual y contribuyen al patrón único de déficits y fortalezas que caracterizan el funcionamiento cognitivo. Sugieren además, que estas anomalías aparecen prenatalmente, antes de que las conexiones dependientes de la actividad se establezcan, con lo cual abren una futura línea investigativa cuyo fin tiene que ver con la detección e intervención temprana del TEA.

Otro estudio interesante, con adultos, es el que llevaron a cabo Lai, Lombardo, Auyeung, Chakrabarti y Baron-Cohen (2015), quienes propusieron investigar las diferencias neuroanatómicas en las estructuras que controlan el lenguaje de hombres adultos con autismo. Para ello, seleccionaron 80 hombres de 18 a 41 años diagnosticados como trastornos generalizados del desarrollo (TGD) en el Manual diagnóstico y estadístico de los trastornos mentales- IV Edición (DSM IV). Se les administró una serie de pruebas entre las que se encontraba la Wechsler Abbreviated Scale of Intelligence (WASI) (Wechsler, 1999). Además, los participantes fueron escaneados utilizando equipos de RM con 8 canales de recepción. Lo que señalan como más sorprendente es que las estructuras relacionadas con el lenguaje (por ejemplo, las áreas de Broca y de Wernicke) no estuvieron asociadas con una historia de retraso del lenguaje. Dicho retraso se asoció con un mayor volumen total de materia gris, volumen relativo menor en la ínsula bilateral, ganglios basales ventrales y estructuras temporales superiores, medias y polares, y un mayor volumen relativo en la protuberancia y en el bulbo raquídeo en la adultez. A pesar de esa heterogeneidad, aquellos sujetos con y sin retardo de lenguaje mostraron una coincidencia significativa en características morfométricas cuando se contrastó con individuos neurotípicos emparejados $(\mathrm{n}=57)$, es decir que más allá de la presencia o ausencia de retraso en el lenguaje y su correlato neuroanatómico, los sujetos con TEA presentaban coincidencias neuroanatómicas especificas (Lai et al., 2015).

Como mencionamos supra, Amaral et al. (2008) dividían dos grandes teorías al interior de la perspectiva neuroanatómica del autismo: la que investiga el crecimiento del volumen total del cerebro, y la que se focaliza en el aumento de la materia blanca -no gris- en el cortex cerebral. Respecto a la segunda, Herbert et al. (2003a) demuestran diferencias significativas en la morfología del cerebro de los niños con TEA haciendo hincapié en la sustancia blanca y gris. Compararon los cerebros de niños autistas y de edad escolar normal de alto funcionamiento utilizando un perfil morfométrico de todo el cerebro que incluía tanto el volumen total del cerebro como los volúmenes de todas las regiones principales. Se realizó un análisis morfométrico basado en RM en los cerebros de 17 sujetos autistas y 15 sujetos de control con edades comprendidas entre 7 y 11 años. Los datos arrojados permitieron concluir que la 
sustancia blanca cerebral mostró una tendencia a ser desproporcionadamente mayor en niños con TEA, mientras que la corteza cerebral, el hipocampo y la amígdala mostraron tendencias hacia una desproporción menor. También se reportó otro estudio del mismo autor, un año después, pero en sujetos con trastorno del desarrollo del lenguaje (Herbert et al., 2004). Los niños presentaban un aumento del volumen cerebral total, impulsado predominantemente por un aumento significativo en el volumen de la sustancia blanca cerebral.

En el año 2012 un equipo conformado por más de 20 investigadores de la Universidad de Carolina del Norte (Estados Unidos) desarrolló un estudio tendiente a demostrar diferencias en las fibras de la materia blanca presentes en niños con sospecha de autismo de 6 a 24 meses de edad, con el propósito de realizar diagnósticos tempranos y desarrollar alternativas terapéuticas. Para llevar a cabo este trabajo seleccionaron a 92 niños que tenían hermanos mayores con un diagnóstico de autismo. Se les realizó un estudio usando un sistema de RM denominado imagen de tensor de difusión (mediante el cual se obtienen imágenes tridimensionales) y, finalmente, una evaluación de comportamiento. Los hallazgos preliminares sugieren que la fibra de la materia blanca presenta un desarrollo distinto en los niños de alto riesgo que pueden desarrollar síntomas autistas (Wolff et al., 2012). Los valores de 12 de los 15 tractos examinados difirieron significativamente entre los grupos. Para ellos, identificar a los niños con mayor riesgo de presentar TEA, antes de que el síndrome se manifieste, ofrecería la posibilidad de implementar intervenciones que podrían reducir o incluso prevenir la manifestación del síndrome completamente.

Recientemente, Blanken et al. (2015) han centrado el análisis alrededor de dos características de la morfología cortical con diferencias significativas en muestras clínicas de niños con TEA: la gyrificación (el plegamiento cortical) y el espesor cortical. Con la evaluación de la morfología cerebral a través de un continuo con los rasgos autistas, encontraron que los niños en edad escolar sin TEA mostraban una disminución de la gyrificación cortical, mientras que en niños con TEA aumentaba (Blanken et al., 2015).

Como hemos visto, la perspectiva neuroanatómica del autismo se centra principalmente en dos teorías. En la primera de ellas -la del sobrecrecimiento del volumen cerebral-investigadores como Courchesne, Carper y Akshoomoff(2003) por ejemplo, no dudan en afirmar que este aumento del volumen cerebral es exagerado y significativo. Hutsler y Casanova (2016), por su parte, evidencian que estas alteraciones subyacen al fenotipo conductual y contribuyen al patrón único de déficits y fortalezas que caracterizan el funcionamiento cognitivo de los niños con TEA. La segunda teoría desarrollada en este apartado -la que se enfoca en la materia blanca- es llevada adelante por investigadores que conducen estudios con neuroimagen. Como vimos, demostraron que la materia blanca es desproporcionadamente mayor en niños con TEA. Herbert et al. (2004) no sólo concuerdan con esto, sino que también coinciden con la teoría del sobrecrecimiento del volumen cerebral. Esta hipótesis también es defendida por Wolff et al. (2012). La idea de implementar intervenciones tempranas 
para reducir o prevenir la manifestación sintomática del TEA es defendida por los autores anteriormente mencionados. El acento está puesto en la etiología, con el fin de reducir parcialmente los déficits o prevenirlos totalmente.

\section{La perspectiva neurosocial}

Originadas en estudios de neurobiología funcionalista, la perspectiva neurosocial del autismo alude a la sumatoria de mecanismos nerviosos que organizan nuestras interacciones con los otros, es decir, al modo en que nuestros cerebros empatizan con otros y moldean la información proveniente del mundo externo. Para Cadaveira y Waisburg (2015) cada vez que nos relacionamos con otro ser humano, nuestros cerebros se entrelazan. Esto quiere decir que cada vez que establecemos contacto con otros, nuestros cerebros (preparados biológicamente para ello) realizan interconexiones fluidas para guiar el desarrollo de las relaciones sociales (Gazzaniga, 2009).

En el marco de esta perspectiva, delimitamos dos grandes teorías por su impacto y difusión en las investigaciones actuales sobre autismo: la teoría del "cerebro social" (Dunbar, 1998) y la teoría de empatización-sistematización (E-S) (Baron-Cohen, 2002).

La primera fue desarrollada por Dunbar (1998), antropólogo, psicólogo y biólogo británico, quien extrapoló sus estudios con primates a los seres humanos para entender cómo funcionan las interacciones, la comunicación, el engaño, siendo la empatía el modelo básico de estudio. Como antecedente, el autor sitúa que en el campo cognitivo y neurocientífico se asumía que los cerebros evolucionaban para procesar información factual sobre el mundo. Por lo tanto, la mayor parte de la atención centró en el reconocimiento de patrones, en la visión de color y en la percepción del habla. Por extensión, se supuso que los cerebros evolucionaban para hacer frente a tareas esencialmente ecológicas de resolución de problemas. Dunbar (1998) explica el fenómeno por medio del cual tanto los primates como los humanos, tienen el cerebro más grande que otras especies porque necesitan procesar la información de su contexto ecológico. Una hipótesis alternativa ofrecida a finales de los años ' 80 fue que los primates tienen grandes cerebros porque reflejan las demandas computacionales de los complejos sistemas sociales. Por ende, se infiere que los sistemas sociales de los primates son más complejos que los de otras especies y pueden además involucrar procesos tales como el engaño. Rápidamente, la sugerencia fue que esta hipótesis fuese denominada "inteligencia maquiavélica", aunque hay una creciente preferencia por llamarla teoría del cerebro social (Dunbar, 1998) o de la cognición social (Herpertz y Bertsch, 2014). El término "cognición social", sin embargo, no refiere necesariamente a mecanismos cerebrales, también puede aludir a procesos cognitivos, los cuales presentan una serie de particularidades en el autismo (Alessandroni, Vietri y Krasutzky, 2017). La idea que se desprende de la teoría del "cerebro social" es que permite reconocer determinadas perturbaciones en la sociabilidad y sus correlatos neuroestructurales, pero no sólo en el autismo, sino 
también en la esquizofrenia o en trastornos de la personalidad (Herpertz y Bertsch, 2014; Álvaro- González, 2015).

Por su parte, Pelphrey, Shultz, Hudac y Vander Wyk (2011) presentan un modelo de autismo que describe un fracaso temprano e inicial para desarrollar las funciones especializadas de una o más estructuras neuroanatómicas involucradas en el procesamiento de la información social. Para ellos, el desarrollo del cerebro de un sujeto con autismo es anormal porque evoluciona en un mundo altamente social sin los sistemas neuronales especializados que normalmente le permitirían participar en el tejido de la vida social, y esa canalización cerebral, en cierto sentido distinta, da lugar a otros déficits conductuales característicos del autismo como las deficiencias en la comunicación, los intereses restringidos, estereotipados y los comportamientos repetitivos. Demuestran así, en una investigación con neuroimagen funcional, la implicancia del surco temporal posterior como actor clave en el conjunto de estructuras neurales que dan lugar a los TEA (Pelphrey, Shultz, Hudac y Vander Wyk, 2011).

Hemos visto cómo la teoría del "cerebro social" se inscribe en el campo de una neurobiología funcionalista y permite reconocer determinados trastornos en la sociabilidad a partir de su correlato neuroestructural, tanto para el TEA como para otros trastornos.

Como mencionamos al comienzo, delimitamos al interior de la perspectiva neurosocial la teoría del "cerebro social", desarrollada recientemente, y la teoría de E-S. La segunda de ellas tiene su antecedente en la teoría del "cerebro masculino extremo" (CME) (Baron-Cohen, 2002), cuyo representante principal es Baron-Cohen. A mediados de los años '90, el autor indagó si el autismo era una forma extrema de cerebro masculino. A esta pregunta le antecedía un profundo interés en su enfoque por la diferenciación entre hombres y mujeres no desde un punto vista biológico y anatómico, sino neurocognitivo. Baron-Cohen y Hammer (1997) afirmaban que un sujeto que presenta un cerebro masculino era aquel cuyas habilidades espaciales estaban por delante de sus habilidades sociales, independientemente de su sexo biológico, cromosómico (esto es, que la madre de ese sujeto podría tener un tipo de cerebro masculino), y viceversa. El autor denomina al cerebro femenino como "espacial" y al masculino, "social", aunque luego se retracta por parecerle una distinción que excluye otras habilidades superiores como la atención, el lenguaje, etc. (Baron-Cohen y Hammer, 1997). Sin embargo, no dudaba en delimitar al género como posible causa del autismo. Para defender esta idea, destacaba que, según Rutter, la proporción sexual en el caso del autismo era de 4:1 (hombres/mujeres) mientras que, según Wing, era de 9:1, y concluía que "el autismo (y el síndrome de Asperger) tiene una fuerte relación con ser hombre" (Baron-Cohen y Hammer, 1997, p. 7). Recordemos que, como dijimos, el CDC (2014) también señala este fenómeno en la actualidad, aseverando que existen cinco veces más casos de autismo en varones que en mujeres. Pero cabe mencionar que estos datos descriptivos y estadísticos del CDC (2014) se refieren al sexo biológico, anatómico, mientras que desde la teoría 
de Baron-Cohen (2002), se podría pensar que la referencia es a un tipo de género "cerebral" -neurocognitivo- que se podría encontrar tanto en hombres como en mujeres.

Posteriormente (2005) Baron-Cohen amplió su teoría inicial sobre el CME, y propuso denominarla teoría de E-S. En ese marco, la empatización sería la capacidad de predecir y responder al comportamiento de otros infiriendo sus estados mentales y respondiendo a éstos con una emoción apropiada. En tanto, la sistematización, la capacidad de predecir y responder al comportamiento de los sistemas mediante el análisis de las relaciones entrada/salida e inferir las reglas que gobiernan dichos sistemas (Baron-Cohen, Knickmeyer y Belmonte, 2005, p. 819). El autor argumentó que el cerebro de sistematización es autístico -o lo que él llama CME- y que ello permitiría explicar los islotes de capacidad observados en algunas personas autistas con síndrome de Asperger. En este último caso, lo llama un cerebro de hipersistematización, ya que le permitiría a un niño con autismo predecir basándose en las reglas que gobiernan los sistemas (por ejemplo, la detección de cambios en una rutina). Como contracara, los niños autistas tendrían retrasos y déficits en el sistema de empatización, es decir, en la posibilidad de atribuir estados mentales a los otros. Para Baron-Cohen (2002), la teoría de la mente sería el componente cognitivo de la empatización, mientras que un segundo componente sería el elemento de respuesta: tener una reacción emocional apropiada a los pensamientos y sentimientos de otra persona (Baron-Cohen, 2002). Dentro de la sistematización existirían, desde su concepción, siete clases o agrupamientos que el cerebro podría analizar (BaronCohen, 2010): (i) sistema técnico: una computadora, un instrumento musical ; (ii) sistema numérico: calendarios, horarios del tren; (iii) sistema abstracto: la sintaxis del lenguaje o la notación musical; (iv) sistemas sociales: una elección política, un sistema legal; (v) sistemas naturales: una planta, un fenómeno climático; (vi) sistemas motores: una técnica deportiva o musical; (vii) sistemas de colección: distintos tipos de piedras o maderas.

Entonces, tanto la empatización como la sistematización permitirían explicar los síntomas considerados fundamentales del autismo: la empatización, en lo relativo a la comunicación social que involucra la inferencia de estados mentales de los otros, la sistematización, por otro lado, en cuanto a las reglas que gobiernan los sistemas que están presentes en los intereses restringidos, en las conductas repetitivas y en la adhesión a rutinas y rituales. Consideramos en este punto que la teoría que desarrollamos se yuxtapone con la primera, puesto que tienen los mismos intereses de investigación: el modo en que los cerebros se entrelazan y se modifican en las interacciones con los otros. Asimismo, podríamos inferir que esta perspectiva en general se complementa con la neuroanatómica puesto que necesita conocer las regiones cerebrales, los circuitos neuronales, y la morfología cerebral en general. Sin embargo, mientras que para la perspectiva neuroanatómica las alteraciones manifestadas en niños con autismo son producto de anomalías cerebrales, sea a nivel de la sustancia blanca o del crecimiento anormal del cerebro, para la perspectiva de corte neurosocial, las alteraciones residen en el modo en el que el cerebro se entrelaza 
y se vincula con el medio ambiente. Hemos visto cómo para Pelphrey, Shultz, Hudac y Vander Wyk (2011) el desarrollo anormal del cerebro se debe a que los niños con TEA presentan una canalización cerebral distinta que da lugar a déficits conductuales particulares como las deficiencias en la comunicación, los intereses restringidos, estereotipados y los comportamientos repetitivos.

Por otra parte, es necesario destacar que la perspectiva neurosocial que desarrollamos emplea herramientas metodológicas provenientes de diferentes ámbitos (medicina, neurología, psicología, etología, entre otras). Su particularidad reside en que extrapola el funcionamiento cerebral a los vínculos con el medio ambiente: las interacciones con otros, la comunicación, el lenguaje, el engaño, entre otros. Asimismo, sostiene una concepción evolucionista del cerebro hacia sistemas más complejos para procesar la información proveniente del mundo externo (Dunbar, 1998).

\section{La perspectiva genética}

Aunque inicialmente en los años '80 y '90, ya estaban sentadas las bases para la construcción de una genética del autismo, a partir de 1990 se asumió que los principales estudios de genoma y de asociación de genes "candidatos" conducirían más directamente a los genes comunes del autismo. Si bien el progreso fue lento, el crecimiento de literatura específica es sustancial (véase Figura 2). Para la revisión sistemática de esta perspectiva, se han utilizado las palabras clave en idioma inglés: "genetic", "autistic spectrum disorder", "neurobiology" y "autism", sólo durante el periodo 2015-2017, el número de artículos vinculados a PubMed es de 2143, lo cual contrasta, aleatoriamente, con el periodo 2004-2006 donde el número de artículos que hace referencia a la genética del autismo fue de 741. Realizando otro contrapunto se puede notar en Fig. 2 que la primera publicación respecto a esta área de investigación corresponde a los años ' 70 , pero el número de artículos incrementa en los ' 80 , momento de consolidación de la genética del autismo. En la década del '90, por ejemplo, sólo se escribieron 250 artículos, pero en la década siguiente (20002009) se publicaron 1649 trabajos enmarcados en esta perspectiva.

Para Lai et al. (2014) la arquitectura genética del autismo ha demostrado ser compleja y heterogénea, como lo informan los estudios de citogenética, vinculación o asociación del genoma completo, y la secuenciación de todo el genoma o el exoma. La mayoría de los autores que desarrollan sus estudios en esta perspectiva mencionan presencia o ausencia significativa de determinados genes, de alteraciones genómicas, sin embargo no arriesgan a concluir que alguna de ellas sea la causa del autismo.

Betancur (2013) realizó una revisión exhaustiva de todos los trastornos genéticos reportados en sujetos con autismo o comportamiento autista, identificando 103 genes y 44 desequilibrios genómicos recurrentes y afirman que esos hallazgos contrastan con quienes afirman que se conoce poco acerca de su etiología.

En Estados Unidos, Miles (2011) sostiene que el mayor progreso hacia la identificación de las causas genéticas del autismo provino de la identificación de 


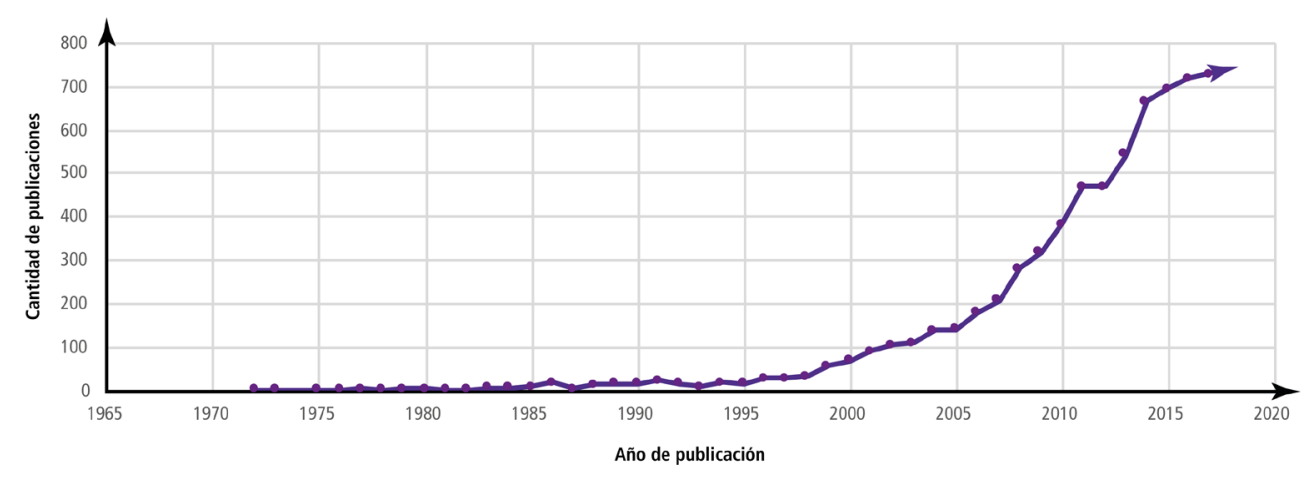

Figura 2. Cantidad de publicaciones por año de publicación

mutaciones y trastornos genéticos conocidos que pueden predisponer al desarrollo del autismo. Utilizando técnicas de evaluación genética médica estándar, se puede identificar una causa genética en el 20-25\% de los niños con TEA (Miles, 2011). Propone que dichas causas se puedan clasificar como: deleciones o variantes del número de copias (VNC) y duplicaciones submicroscópicas (con frecuencia de 10$20 \%$ ); anomalías cromosómicas visibles citogenéticamente (5\% de casos de niños con TEA) y trastornos de un solo gen ( $5 \%$ de los casos). Respecto a la primera variante, afirma que se identificaron anomalías citogenéticas en casi todos los cromosomas, aunque sólo unas pocas ocurren con una frecuencia que sugiera la localización de un gen específico de autismo. Las VNC no demuestran unívocamente la causa del autismo. Primero, la penetración es extremadamente variable. Tanto las deleciones como las duplicaciones pueden ser hereditarias u ocurrir de novo, es decir, cuando las mutaciones ocurren por primera vez en una familia. Por último, cuando ocurre que existen trastornos de un solo gen, el autismo en estos casos se refiere a menudo a un "autismo sindrómico" o a lo que la autora llama "autismo de causas conocidas" (Miles, 2011). Este se produciría en condiciones en las que el TEA ocurre junto con fenotipos adicionales y/o características dismórficas.

Otro tipo de clasificación es la que realizan Fariña, Galli, Lazo, Mattei y Raggio (2015), quienes proponen una división de las variedades de estudios genómicos en tres grupos: el primero, incluye la mayoría de los casos y es de etiología multifactorial, siendo su fenotipo el resultado de la interacción genoma-ambiente. Dentro de este tipo de estudios se han detectado variantes genéticas en más de 100 genes que se vinculan al autismo. En este punto, los autores disienten con Miles (2011) quien, como vimos, afirma que se conoce poco acerca de la etiología del TEA. El segundo grupo aúna síndromes genéticos que incluyen al autismo como parte de su espectro fenotípico. En esta línea, Levit y Campbell (2009) afirman que existen síndromes de herencia mendeliana que asocian TEA y fenotipo. Estos darían cuenta de aproximadamente un $10 \%$ de los casos. Otro $5 \%$ está relacionado a alteraciones cromosómicas. Sólo por nombrar los más significativos, incluyen los síndromes de X Frágil, con una frecuencia de co-diagnóstico del 45 al 70\% identificado al gen FMR1, el renombrado síndrome de Rett (categoría que forma parte del DSM IV en los TGD) con una frecuencia del 
$50 \%$, ligado al gen MECP2, y el Síndrome de Down, con frecuencia del 5 al 15\%, vinculado a la trisomía del cromosoma 21. Por último, el tercer grupo, tiene un perfil fenotípico específico, basándose su etiología en mutaciones de novo de efecto mayor. Se trata en este caso de estudios realizados a través de nuevos métodos de mayor resolución (como la tecnología de microarrays) que permitieron descubrir nuevas mutaciones -microduplicaciones y microdeleciones- "que no podían ser detectadas por estudios convencionales" (Levit y Campbell, 2009, p. 14). Este tipo de estudios es al que hacen referencia las investigaciones de Lai, Lombardo y Baron-Cohen (2014) y Miles (2011), citados anteriormente.

Una línea de investigación fecunda dentro de esta perspectiva refiere al estudio de los métodos, por medio de los cuales los distintos investigadores logran realizar un análisis minucioso y certero de los procesos neuronales y genéticos del autismo. Es importante destacar aquí que, aunque las técnicas de neuroimagen del cerebro humano han identificado regiones y circuitos implicados en los trastornos, numerosos autores coinciden en optar por el estudio de modelos de patologías o síndromes en animales, más específicamente, de ratones (Xu, Miller y Pozzo-Miller, 2014; Lombardi, Baker y Zoghbi, 2015; Hulbert y Jiang, 2016; Sztainberg y Zoghbi, 2016; Fuccillo, 2016; Wang et al., 2017).

Actualmente, en el ámbito de la investigación básica-traslacional, se cuenta con modelos murinos para el desarrollo de diferentes líneas de investigación abocadas a los TEA. Los ratones transgénicos (o manipulados genéticamente para los fines de la investigación) permiten estudiar aspectos y roles específicos en este escenario. Han sido utilizados ratones que sobreexpresan o carecen del gen MCEP2 [methyl CpG binding protein 2] como también aquellos donde la manipulación genética permite realizar VNC en el cromosoma 16p11.2. La mayor parte de los trabajos publicados sobre la expresión genética condicional para el autismo implica la manipulación de los genes que están mutados en el autismo sindrómico, como el Síndrome de Rett (MECP2) y el complejo de esclerosis tuberosa (TSC1 o TSC2). Consideramos que la posibilidad de manipular genéticamente estos animales abre un sin número de posibilidades ya que recapitulan la mayoría de los defectos del desarrollo y permiten ahondar en la comprensión del TEA.

Asimismo, se han encontrado escasos artículos que hayan incluido en su muestra otras especies animales para el estudio del autismo. Un ejemplo de ello es el que emprendieron Liu et al. (2016), quienes utilizaron monos transgénicos para observar las mutaciones en el gen MECP2 que se encuentra en el 90\% de los pacientes con Síndrome de Rett. Los hallazgos les permiten afirmar que los monos transgénicos que expresan MECP2 humano en el cerebro muestran por un lado, la transmisión germinal del gen, $y$, por otro, conductas de retraimiento social similares a las que pueden encontrarse en casos de TEA (Liu et al., 2016). Generalmente, los estudios con ratones ofrecen oportunidades para la manipulación directa de las regiones y de los circuitos cerebrales. Sin embargo, una limitación para este tipo de estudios es que no existe ninguna característica neuropatológica singular identificada hasta 
el momento que sea patognomónica, por lo cual varios investigadores se proponen determinar la validez de un modelo animal de autismo (Hulbert y Jiang, 2016). Los estudios en esta línea comparan el comportamiento entre humanos y ratones por varias razones: la similitud genética y biológica, la reproducción rápida en tiempo, y el bajo coste económico (Hulbert y Jiang, 2016).

Sztainberg et al. (2015) realizaron una investigación basada en un modelo animal, tomando la clásica distinción entre autismo sindrómico y no sindrómico. Los autores proponen que la restauración y corrección de los niveles normales de MECP2 en la duplicación evidenciada en ratones adultos, rescataría el fenotipo e invertiría ampliamente los déficits conductuales, moleculares y electrofisiológicos. En la mayoría de las personas con autismo sindrómico la etiología es conocida y puede deberse a anomalías, VNC submicroscópicas y mutaciones en un solo gen, como en el síndrome X frágil, el síndrome de Rett, síndrome de duplicación del MECP2, complejo de esclerosis tuberosa y síndrome de macrocefalia. Por el contrario, el autismo no sindrómico se refiere al autismo clásico descrito por Kanner (1943), el cual no presenta otros síndromes asociados. Existen muy pocos conocimientos sobre la causa de TEA no sindrómico (Sztainberg et al., 2015), sin embargo la evidencia acumulada por estudios realizados durante más de 40 años proporcionaron la idea de componentes genéticos involucrados. Sztainberg et al. (2015) sostienen que esto llevó a muchos laboratorios a investigar sobre loci asociados con riesgo genético de TEA mediante el uso de análisis de vinculación genética y de asociación en todo el genoma. Por otro lado, que la corrección de los niveles del gen MECP2 invierte ampliamente los déficit conductuales, moleculares y electrofisiológicos (Sztainberg et al., 2015). Esta última cuestión se revisará con detenimiento en la siguiente sección.

En otro artículo de aparición reciente, Wang et al. (2017) proponen estudiar los efectos de la duplicación del gen MECP2 y la duplicación del cromosoma humano 15q11-13 sobre el desarrollo sináptico y el cableado del circuito neural en las cortezas sensoriales del ratón. Los autores tomaron como punto de partida dos cuestiones: por un lado, que los ratones que llevan la duplicación del gen MECP2 tenían defectos específicos en la poda de la columna vertebral; por otro lado, que la duplicación del 15q11-13 había deteriorado la formación de la columna vertebral de los ratones. Sobre esos resultados infirieron que las deleciones maternas de esa región dan lugar al Síndrome de Angelman, las paternas, al Síndrome de Prader-Willi, mientras que su duplicación representa una de las VNC más frecuentemente reportadas en los TEA (Wang et al., 2017). En esta línea, pero con claros propósitos clínicos, Lombardi, Baker y Zoghbi (2015) focalizaron su estudio en los desórdenes producidos en el gen MECP2, subrayando que la reversibilidad de los fenotipos en el modelo de ratón con Síndrome de Rett (y con trastornos en MECP2) beneficia una potencial intervención terapéutica en pacientes humanos. Sin embargo, los autores sugieren prudencia en la transición que se hace a pacientes humanos ya que el camino a la traducción clínica está repleto de desafíos.

Otra línea de investigación de corte genetista y con fuerte peso en el ámbito científico 
es la que sostiene la heredabilidad del autismo. De entrada, podemos situar esta cuestión en uno de los precursores de la psiquiatría infantil del autismo. Nos referimos al psiquiatra Hans Asperger, quien en su descripción de la psicopatía autística eleva lo hereditario a la categoría de la causa (1944). Esto es constatado por el autor en la casuística analizada, entre los ascendientes del niño, sus padres y otros parientes con rasgos psicopáticos emparentados. Con este antecedente y a partir de los años ' 70 , diferentes estudios familiares y de gemelos muestran que los TEA son altamente hereditarios y muchas veces se producen en contextos de riesgos ambientales (Folstein y Rutter, 1977; Lai et al., 2014; de la Torre-Ubieta, Won, Stein, y Geschwind, 2016; Tick, Bolton, Happé, Rutter, y Rijsdijk, 2016). El análisis que llevaron a cabo Folstein y Rutter (1977), por ejemplo, consistió en tomar 21 parejas de gemelos del mismo sexo, donde uno de ellos era considerado autista bajo los criterios diagnósticos utilizados por Kanner y Rutter. Los resultados arrojaron datos significativos para demostrar la importancia de la heredabilidad en la etiología del autismo (Folstein y Rutter, 1977). La mayoría de las parejas de gemelos analizadas evidenciaron lesiones cerebrales, especialmente durante el periodo prenatal. No obstante, concluyeron que en este campo no hay certezas etiológicas.

Distintos investigadores concuerdan en que los estudios de gemelos muestran una alta heredabilidad del autismo, estimada en un $90 \%$ de los casos. Por otro lado, en que la tasa de recurrencia en hermanos de niños con autismo puede llegar hasta el 8\% (Cabrera, 2007; Espin Jaime, Cerezo Navarro y Espin Jaime, 2013; Geschwind y State, 2015).

En resumen, la perspectiva genética del autismo lleva adelante estudios en al menos tres líneas de investigación bien definidas: las que buscan evidencia para establecer la causa del autismo, las que se enfocan en el estudio de modelos animales y las que reparan en la heredabilidad genética.

En la primera de ellas, observamos ciertas contradicciones en cuanto a la concepción que mantienen sobre la etiología. Para Miles (2011), por ejemplo, la evidencia genética arroja luz sobre la causa. Releva estudios que promueven la identificación de genes candidatos, de mutaciones y de trastornos genéticos que pueden predisponer al autismo. Del mismo modo, Sztainberg y Zoghbi (2016) sostienen que dicha evidencia sobre la etiología genética tiene una innegable tradición de cuarenta años. Sin embargo, otros autores como Fariña, Galli, Lazo, Mattei y Raggio (2015) son más cautelosos en cuanto a establecer la causa. Para ellos, las líneas de investigación que se enfocan en la interacción genoma/ambiente detectan variaciones en más de 100 genes. Por ende, concluyen que no se podría explicar la patogenia rápidamente, ya que su etiología es multifactorial. Para Folstein y Rutter (1977), por el contrario, en el autismo no hay certezas etiológicas. Así, consideramos que las posturas en cuanto a la etiología podrían estar divididas en tres: aquellas que plantean que existe una evidencia empírica suficiente para sostener que la causa es genética e identificable; aquellas que afirman que aún no existen certezas etiológicas, y las que consideran que la causa del autismo es multifactorial. 
En la segunda línea de investigación enmarcada en esta perspectiva, la mayoría de los autores conducen estudios con modelos de patología en animales (mayormente de ratones pero también con monos transgénicos) y focalizan en los desórdenes producidos en el gen MECP2 y el cromosoma 15q11-13. Vimos por ejemplo con Wang et al. (2017) que los ratones que llevan la duplicación del gen MECP2 tenían defectos específicos en la poda de la columna vertebral y que la duplicación del 15q11-13 había deteriorado la formación de la columna vertebral de los ratones.

Por último, la línea de investigación que estudia la heredabilidad del TEA incluye mayoritariamente estudios de gemelos (véase Tabla 2). Hemos visto que existe un consenso general entre los autores al establecer una alta heredabilidad del autismo, estimada en un $90 \%$ de los casos.

En la sección siguiente veremos cómo la perspectiva genética del autismo se complementa y se entrecruza con los de la neuroquímica y enriquece los estudios sobre neuroanatomía. Respecto a la perspectiva neuroquímica, analizaremos particularmente una línea de investigación ligada a la oxitocina (OXT) y la arginina vasopresina (AVP), asociadas por los autores al autismo.

\section{La perspectiva neuroquímica: las vías OXT y AVP}

En esta perspectiva se han investigado los genes neuropeptídicos en relación con el autismo debido a la creciente evidencia de que la OXT y la AVP- también conocida como la hormona antidiurética- tienen un papel importante en la regulación del comportamiento filiatorio y en el vínculo social de mamíferos humanos y no humanos (Heinrichs y Domes, 2008; Álvaro- González, 2015; LoParo y Waldman, 2015). Existe consenso, al interior de esta perspectiva, en afirmar que tanto la AVP como la OXT actúan en el sistema nervioso central y que los desórdenes que se producen en ellas podrían relacionarse a la patogénesis del autismo (Wu et al., 2005; Hollander et al., 2007; Ishak, Kahloon y Fakhry, 2011; Domes et al., 2013; Zhang, Zhang, Han y Hang, 2017). Se incluyen en esta sección aquellos artículos basados en el estudio de estas hormonas en particular y su relación con el autismo. Se podría definir a la OXT como la hormona que media en las conductas sociales y filiatorias como la compasión, por ejemplo, que sería una forma de emoción social compleja. Esta hormona se produce en los núcleos supraóptico y paraventricular del hipotálamo y se acumula y libera en la hipófisis posterior. Álvaro- González (2015) afirma que la OXT se ha relacionado con el apego materno-filial, desde el mismo momento del parto en el que se liberan grandes cantidades al líquido cefalorraquídeo y al torrente sanguíneo. Se la conoce también como "la hormona del amor romántico, de la confianza y del reconocimiento de caras” (Álvaro- González, 2015, p. 466).

Al igual que en la perspectiva genética y que en la perspectiva neurosocial, la neuroquímica también se sirve de modelos de patología en animales y de otros específicamente humanos. Los primeros han demostrado la influencia de la OXT y de sus receptores (OXTR) en la mediación de los comportamientos sociales, 


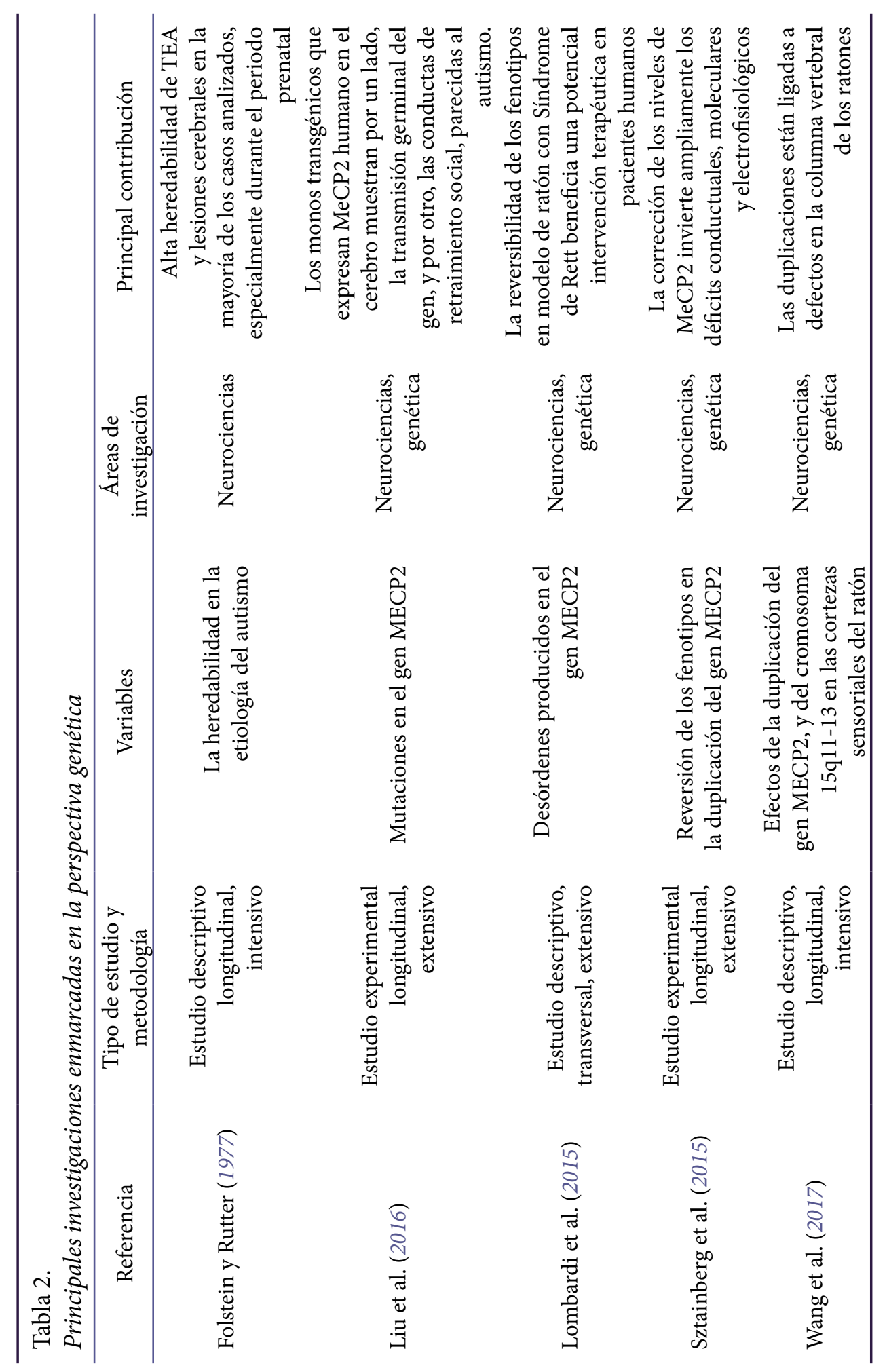


particularmente en roedores (Pobbe et al., 2012; Clipperton-Allen, Chen y Page, 2016) sugiriendo que los fracasos en este sistema contribuyen a los déficits en la interacción social que caracterizan a los TEA. En humanos, la función de la OXT y sus efectos en los TEA presenta multiplicidad de estudios. Uno de ellos es el de Aoki et al. (2014) que tuvo como fin estudiar el efecto potencial de la OXT en las evidentes dificultades en la comprensión de las emociones y en las creencias sociales de otros. Utilizaron como recurso un estudio de casos y controles, y un ensayo clínico mediante RM funcional durante una tarea psicológica. La misma consistía en una actividad similar a la de las clásicas muñecas de Sally-Anne, enmarcadas en los estudios de teoría de la mente y en la tarea de falsa creencia. Los autores demostraron que la OXT aumentó significativamente en los pacientes con autismo al inferir las emociones sociales de los demás.

Por su parte, Ishak, Kahloon y Fakhry (2011) realizaron una revisión sistemática través de una búsqueda en Medline, Pubmed y PsychINFO, con el fin de investigar el rol de la OXT y su vinculación con los TEA y otros trastornos. El término de la búsqueda era la referencia de OXT con el comportamiento filial, con la confianza, el miedo, la vinculación, el comportamiento sexual, el autismo, los desordenes psiquiátricos y la psiquiatría en general. Marcan algunos datos significativos sobre este análisis que relacionaron con tres campos: el bienestar a nivel interpersonal, el bienestar a nivel individual, y sus diversos usos en condiciones neuropsiquiátricas. Respecto al tema que nos interesa, los autores evidencian que los niños con TEA tienen niveles más bajos de OXT en plasma en comparación con grupos de igual edad (IsHak et al., 2011).

Wu et al. (2005) apoyaron sus estudios en la prueba genética denominada family-based association test [Test de asociación basado en la familia]. La misma fue administrada a 195 tríos de personas de nacionalidad china (los dos padres biológicos y un niño con diagnóstico de TGD). Los resultados les permitieron aseverar que existe una significativa asociación genética entre autismo y dos de los polimorfismos de un sólo nucleótido (PSN) probados. Rescatan, además, los aportes del psiquiatra Hollander (2003, 2007), quien propone dos fuertes evidencias en el campo: la eficacia de la infusión de OXT sintética sobre las conductas repetitivas del autismo (Hollander et al., 2003) y los efectos positivos de la administración intravenosa de OXT sobre la retención de información social en el autismo (Hollander et al., 2007). En el primer estudio, para probar la eficacia de la OXT sobre las conductas repetitivas, evaluaron a 15 pacientes adultos diagnosticados como trastorno autista o como trastorno de Asperger según los criterios del DSM IV y los criterios de la entrevista de diagnóstico de autismo - revisado (ADI-R) (Lord, Rutter y Le Couteur, 1994). En las evaluaciones los pacientes recibían OXT y placebos, y se les administró un instrumento que calificaba seis comportamientos repetitivos: la necesidad de saber, de repetir, de ordenar, de decir/ preguntar, de autolesionarse y de tocar (Hollander et al., 2003). Los datos obtenidos les permitieron concluir que "con la administración de oxitocina (...) disminuyeron con el tiempo no sólo la gravedad de los comportamientos, sino también el número de diferentes tipos de comportamientos repetitivos" (Hollander 
et al., 2003, p. 196).

La idea de un tratamiento exógeno vía OXT (intranasal y/o intravenoso) se impuso fuertemente en los últimos años. Domes et al. (2013), por ejemplo, estudiaron los efectos de OXT administrada intranasalmente a sujetos con TEA. En su metodología incluyeron a un grupo de 14 individuos con síndrome de Asperger y un grupo de 14 participantes neurotóxicos de control, a los que se les aplicó RM funcional. Los resultados permitieron demostrar que en el grupo con síndrome de Asperger disminuyó la actividad en la amígdala derecha, en el giro fusiforme y en el occipital inferior, en comparación con el grupo control. Para los autores, los hallazgos indican que la OXT aumenta la recepción de los estímulos sociales, y sugieren que esta hormona podría promover el tratamiento facial y el contacto visual en individuos con TEA como requisitos previos para la interacción social neurotípica.

Por su parte, Andari et al. (2010) llevaron adelante una interesante investigación, administrando también OXT vía intranasal. Analizaron los efectos producidos en el comportamiento de 13 sujetos con TEA en un juego de pelota simulado. En el mismo, los participantes interactuaron con parejas ficticias, y descubrieron que después de la inhalación, los pacientes exhibían interacciones más fuertes con la pareja, eran socialmente más cooperativos y con mayores sentimientos de confianza.

La eficacia de los tratamientos exógenos con OXT empieza a ser fuertemente investigada y cuestionada. Young y Barrett (2015) problematizan tres puntos principales: (i) que la concentración de OXT en sangre y el genotipo del gen receptor de la OXT (OXTR) se asocian fuertemente con la cognición social pero no con el diagnóstico de TEA específicamente; (ii) que los estudios en este campo se encuentran todavía en las primeras etapas y, por ende, no puede haber aún resultados contundentes; y (iii) que, debido a (i) y (ii), no hay suficientes datos para que los médicos prescriban OXT a los pacientes o para que los padres busquen OXT para sus hijos con TEA.

Más allá de este controvertido debate, los investigadores sugieren que el aumento de la información sobre los mecanismos de los estudios en animales, la optimización actual de los paradigmas terapéuticos y el desarrollo de enfoques de próxima generación para dirigir el sistema de OXT puede conducir a la mejora de la función social en los TEA y en otros trastornos psiquiátricos (Young y Barrett, 2015). Muy recientemente, Shou et al. (2017) propusieron explorar los cambios concomitantes en los comportamientos de los niños autistas, los niveles circulantes de AVP y la conectividad estructural y funcional de las regiones cerebrales específicas, a través de $\mathrm{RM}$ en comparación con niños de desarrollo típico de 3 a 5 años. Con este objetivo, describieron el procedimiento de forma oral a los padres de 21 niños, con sesiones de preguntas y respuestas. 19 de los 21 completaron la RM y dos fueron excluidos: uno por presentar antecedentes de epilepsia, y otro porque despertó durante la evaluación. En su estudio encontraron evidencia de que la gravedad de los TEA se asocia con cambios en la morfología y en la funcionalidad de las regiones cerebrales donde los sistemas AVP están involucrados. Concluyen: "ese patrón anormal es el que haría 
percibir la información como aversiva, causando el fracaso en el establecimiento de la red social" (Shou et al., 2017, p. 138).En suma, distintas investigaciones evidencian que la OXT tiene un papel fundamental en la regulación del comportamiento filial y social, de allí que los estudios emprendidos busquen en el autismo, desórdenes en esta hormona. Sin embargo, para LoParo y Waldman (2015), el acento debe estar puesto en el OXTR, estudiado como un factor de riesgo para el TEA. Los autores propusieron una revisión meta-analítica de los estudios existentes para determinar si el OXTR muestra asociación con los TEA, y para poder dilucidar qué PSN tienen un efecto significativo en este trastorno. Encontraron 16 OXTR y PSN que incluían 3941 individuos con TEA de 11 muestras independientes. Se hallaron asociaciones significativas entre TEA y los PSN rs7632287, rs237887, rs2268491 y rs2254298. El OXTR también estuvo asociado significativamente con TEA en una prueba basada en los genes (LoParo y Waldman, 2015).

Como venimos sosteniendo, la idea de establecer una etiología para el TEA tiene como fin la necesidad de establecer diagnósticos y tratamiento más tempranos. Las investigaciones sobre tratamientos con OXT son una prueba de ello (véase Tabla 3).

Podríamos concluir que existe consenso en afirmar que los desordenes en las vías OXT y AVP se vinculan a la patogénesis del TEA. En esta perspectiva como en la genética, el hecho de establecer una etiología precisa se vuelve fundamental. Ambas se complementan. Lo confirman las investigaciones de Wu et al. (2005), por ejemplo, quienes posicionados desde una perspectiva neuroquímica incluyen en sus estudios pruebas que son exclusivamente genéticas, pero también los de Young y Barrett (2015) al considerar el papel fundamental que desempeña el OXTR en la cognición social.

Hemos visto que el tratamiento propuesto desde esta perspectiva es exógeno, mediante la administración de OXT, intranasal o intravenosamente (Hollander, 2003, 2007; Andari et al., 2010; Domes et al., 2013). Sin embargo, se ha demostrado que al interior de la perspectiva existe falta de acuerdo, primero al considerar que la concentración de OXT se asocia con la cognición social y segundo, al prescribir OXT terapéutica a niños con autismo.

Como sugieren Zhang, Zhang, Han, y Hang (2017), el enfoque OXT-AVP es potencialmente fructífero para el descubrimiento de fármacos, así como una fuente de biomarcadores potenciales para el diagnóstico precoz de los trastornos sociales y especialmente para los TEA.

\section{Conclusiones y discusión}

En este artículo constatamos, en relación al TEA, la existencia de un campo dentro de las neurociencias denominado neurobiología del autismo. Se trata de un campo científico heterogéneo que se desprende de la biología y que se ocupa de estudiar los aspectos estructurales y funcionales del sistema nervioso central en sujetos con TEA. Consideramos y desarrollamos los fundamentos metateóricos de cuatro 


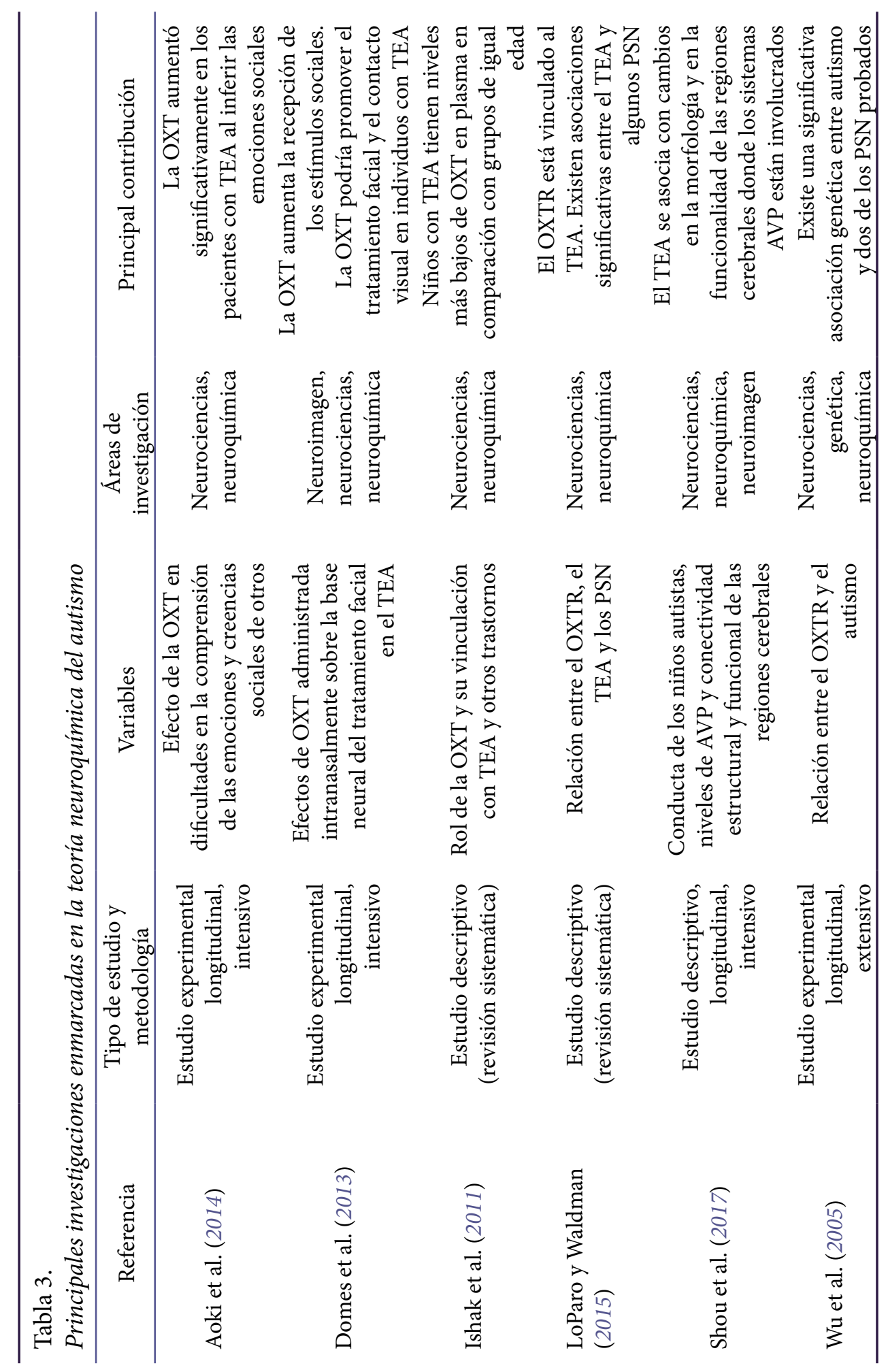


grandes perspectivas que se enmarcan dentro de este campo: (i) la perspectiva neuroanatómica, (ii) la perspectiva neurosocial, (iii) la perspectiva genética y (iv) la perspectiva neuroquímica.

En el marco de la primera describimos diferentes estudios que podrían agruparse en dos grandes teorías: la que estudia el sobrecrecimiento del volumen cerebral en los niños con TEA y el plegamiento cortical (Courchesne, Carper y Akshoomoff, 2003; Hazlett et al., 2011; Wolff et al., 2012; Lai et al., 2014; Blanken et al., 2015; Lai et al., 2015; Hutsler y Casanova, 2016) y la que analiza el aumento de la materia blanca (Herbert et al., 2003a, 2003b, 2004). Revisamos en la sección, las investigaciones que evidencian y dan fundamento a cada una de estas teorías. En segundo lugar, destacamos que esta perspectiva fomenta la implementación de intervenciones tempranas para reducir parcialmente o prevenir de manera total la manifestación sintomática del autismo.

A diferencia de la perspectiva neuroanatómica, la perspectiva neurosocial tiene como objeto de estudio el modo en que los cerebros de sujetos con TEA procesan la información y se relacionan con otros. Delimitamos en su interior dos grandes teorías por su impacto en las investigaciones actuales sobre autismo. Nos referimos a la teoría del "cerebro social" (Dunbar, 1998) y a la teoría E-S (Baron-Cohen, 2002). Hemos visto que la primera, a partir del concepto de cognición social, se ocupa de describir la interacción entre el cerebro y el ambiente. Esta teoría también estudia los correlatos neuroestructurales de algunos trastornos en la sociabilidad. Por otro lado, hemos delimitado en el marco de esta perspectiva, la teoría E-S cuyo representante principal es Baron-Cohen (2002). Definiendo a la empatización como la capacidad de predecir la conducta de los otros infiriendo sus estados mentales y a la sistematización como la capacidad de predecir y responder al comportamiento de los sistemas mediante el análisis de las relaciones entrada/salida, el autor concluye que el cerebro de los niños autistas es predominantemente de sistematización y tendría retrasos y déficits en el sistema de empatización.

En cuanto a la tercera perspectiva (la genética), dimos cuenta del crecimiento exponencial de sus investigaciones en los últimos años. Hemos recortado tres líneas de investigación bien diferenciadas: la que busca evidencia para establecer la causa del TEA, la que se enfoca en el estudio de modelos de patología en animales y la que repara en la heredabilidad del autismo. En la primera de ellas observamos posturas disímiles en cuanto a la concepción que mantienen sobre la etiología. Diferenciamos tres posturas: la que sostiene que la causa es genética e identificable, la que plantea que todavía no existe una certeza etiológica, y la que sostiene que el autismo es de etiología multifactorial. En la segunda línea de investigación, vimos cómo a partir del estudio con modelos de patología en animales (mayormente de ratones pero también con monos transgénicos) se podían observar los desórdenes producidos en el gen MECP2 y en el cromosoma 15q11-13. En último orden, desarrollamos la línea de investigación que estudia la heredabilidad del TEA. Planteamos que existe un consenso general entre los autores al establecer una alta heredabilidad del TEA, 
estimada en un $90 \%$ de los casos y que la tasa de recurrencia en hermanos de niños con TEA puede llegar hasta el $8 \%$.

Las investigaciones neuroquímicas enmarcadas en la cuarta y última perspectiva han priorizado el estudio de las vías de OXT y AVP por el papel que juegan en la regulación del comportamiento filial y social. Observamos que existe consenso en afirmar que hay bajos niveles de OXT en los niños con TEA. Esto llevó a investigar diferentes tratamientos externos para corregir esa diferencia en los niveles de OXT. El consenso, sin embargo, no es suficiente para extrapolar esos resultados a la prescripción de OXT por parte de los profesionales médicos, puesto que sólo se focalizaría en un aspecto del autismo (las alteraciones sociales) y no en el TEA mismo. Una vez más hemos visto allí cómo el acento está puesto en las intervenciones tempranas sobre niños con TEA, y no tanto en el establecimiento de una causa unívoca.

En líneas generales, podríamos pensar que las perspectivas neuroanatómica y genética sirven de base para las teorías y líneas de investigación que desarrolla la perspectiva neurosocial y neuroquímica. Por ejemplo, el estudio del gen OXTR en la perspectiva neuroquímica requiere de los postulados de la perspectiva genética para poder estudiar las vías OXT y AVP. Asimismo, la perspectiva neurosocial se complementa con la genética, haciendo hincapié en la línea que estudia la alta heredabilidad, pero también con la neuroanatómica, puesto que al referirse a la teoría de E-S (y a su antecedente, la teoría del CME), delimita regiones cerebrales específicas y sugiere determinados correlatos anátomo-fisiológicos para explicar las modificaciones cerebrales.

Para ordenar el análisis comparativo de cada una de las perspectivas, se proponen cuatro ejes de análisis: las concepciones sobre la disfunción neurobiológica, el tipo de estudios empleados, las posturas respecto a la etiología del TEA, y los tratamientos propuestos para abordar casos de niños con autismo.

En relación a la disfunción neurobiológica, podríamos decir que la neuroanatómica se basa en el aumento de la sustancia blanca y en el sobrecrecimiento del cerebro y de la corteza. La perspectiva neurosocial, en el correlato que existe entre lo neuroanatómico y las conductas que implican lazo social con los otros (empatía, engaño, falsa creencia, entre otras). Para las perspectivas genética y neuroquímica, la disfunción neurobiológica estará centrada en el estudio de los genes (mayormente en el gen MECP2) y en el cromosoma 15q-11-13, y en las vías OXT y AVP, respectivamente. Es importante destacar que tanto la perspectiva neuroanatómica como la neurosocial comparten la premisa de que las alteraciones manifestadas en niños con autismo (comunicación, lenguaje, intereses restringidos y conductas estereotipadas) son producto de anomalías cerebrales generales. Ello no es así en las perspectivas genética y neuroquímica, cuyos postulados están centrados en la identificación de genes candidatos y en el estudio de hormonas específicas (OXT y AVP).

En cuanto a los estudios utilizados, la perspectiva neuroanatómica utiliza mayormente RM funcional. Mencionamos que la perspectiva de corte neurosocial 
emplea herramientas metodológicas provenientes de diferentes ámbitos (medicina, neurología, psicología, etología, entre otras), a diferencia de otras perspectivas que tienen métodos propios, como la genética y la neuroquímica. Estas últimas comparten entre sí el uso de modelos de patología en animales. La genética utiliza prioritariamente ratones, y la neuroquímica incluye también monos para explorar la OXT.

Los discursos de cada perspectiva en cuanto a etiología son variados. Por ejemplo, en la perspectiva neuroanatómica el acento está puesto en las intervenciones precoces antes que en el establecimiento de la causa. Para la perspectiva neurosocial el autismo es multicausal, está determinado por varios factores. Es en la perspectiva genética donde encontramos posiciones disímiles, aún dentro de un mismo marco teórico. Delimitamos, como dijimos antes, tres posturas: la que afirma que existe un gen identificable, la que plantea que todavía no existe una certeza etiológica, y la que sostiene que el autismo es de etiología multifactorial. Los artículos revisados oscilan entre las tres posiciones. Sin embargo, consideramos que la línea que investiga la heredabilidad del autismo puede dar respuesta a cada una de estas posturas. Asimismo, estimamos la importancia que presenta el avance de tecnologías mas sofisticadas para establecer marcadores genéticos que puedan identificar tempranamente el diagnóstico de autismo.

En relación con los posibles tratamientos para abordar casos de niños con TEA, la perspectiva neuroanatómica postula que ellos podrían lograr reducir parcial o totalmente los síntomas del autismo. La perspectiva neurosocial, por su parte, no presenta hipótesis en cuanto al tratamiento. La perspectiva genética aboga por el establecimiento de los marcadores que identifiquen genes candidatos. Por ello la modificación genética y la extrapolación de estudios de modelos de patología de animales en adultos es un campo particularmente relevante para los defensores de esta perspectiva. Por último, la perspectiva neuroquímica se basa en la administración de OXT intranasal o intravenosa. Los debates al interior de esta perspectiva giran en torno a si la administración de esta hormona revertiría únicamente el déficit social o bien todos los síntomas del autismo.

En función de la descripción y las conclusiones a las que hemos arribado en cada perspectiva, podríamos inferir que la perspectiva neurosocial y la neuroquímica sólo tienen fundamento si se las correlaciona con la neuroanatómica y con la genética. En otras palabras, si bien las cuatro perspectivas se enmarcan en la neurobiología del autismo, la perspectiva neuroanatómica y la genética integrarían en su interior a la neurosocial y a la neuroquímica, tanto por los métodos utilizados, como por las premisas teóricas que subyacen a ellas. 


\section{Referencias}

Acedo-Carmona, C. y Gomila, A. (2016). A critical review of Dunbar's social brain hypothesis. Revista Internacional de Sociología, 74(3), e037. HTTPS://DOI.ORG/10.3989/RIS.2016.74.3.037

Acosta, J., Guzmán, G., Sesarini, C., Pallia R. y Quiróz, N. (2006). Introducción a la neurobiología y neurofisiología del Trastorno del Espectro Autista. Revista Chilena de Neuropsicología, 11(2), 28-33. HTTPs://DOI. ORG/10.5839/RCNP.2016.11.02.05

Alessandroni, N., Vietri, M. y Krasutzky, I. (2017) Atribución de estados mentales y autismo: desarrollos teóricos y controversias actuales. En M. C. Piro (Ed.), El autismo: perspectivas teóricoclínicas y desafíos contemporáneos (pp. 103-150). La Plata: EDULP - Editorial de la Universidad Nacional de La Plata.

Álvaro-González, L. C. (2015). El cerebro social: bases neurobiológicas de interés clínico. Revista de Neurología, 61(10), 458-470.

Amaral, D. G., Schumann, C. M. y Nordahl, C. W. (2008). Neuroanatomy of autism. Trends in Neurosciences, 31(3), 137-145. HTTPS://DOI. ORG/10.1016/J.TINS.2007.12.005

Andari, E., Duhamel, J.-R., Zalla, T., Herbrecht, E. Leboyer, M. y Sirigu, A. (2010). Promoting social behavior with oxytocin in high-functioning autism spectrum disorders. Proceedings of the National Academy of Sciences, 107(9), 4389-4394. HTTPS://DOI.ORG/10.1073/PNAS.0910249107

Aoki, Y., Yahata, N., Watanabe, T., Takano, Y., Kawakubo, Y., Kuwabara, H., ... Yamasue, H. (2014). Oxytocin improves behavioural and neural deficits in inferring others' social emotions in autism. Brain, 137(11), 3073-3086. HTTPS://DOI. ORG/10.1093/BRAIN/AWU231

Asperger, H. (1944). Die “Autistischen Psychopathen” im Kindesalter [Psicopatía autística en la infancia]. Archiv für Psychiatrie und Nervenkrankheiten, 117, 76-136.

Baron-Cohen, S. (2005). Sex differences in the brain: Implications for explaining autism. Science, 310(5749), 819-823. HTTPS://DOI.ORG/10.1126/ SCIENCE.1115455

Baron-Cohen, Simon. (2002). The extreme male brain theory of autism. Trends in Cognitive Sciences, 6(6), 248-254. HTTPS://DOI.ORG/10.1016/ S1364-6613(02)01904-6
Baron-Cohen, Simon. (2004). Autism: research into causes and intervention. Pediatric Rehabilitation, 7(2), 73-78. HTTPs://DOI.ORG/10.1080/1363849031 0001654790

Baron-Cohen, Simon. (2010). Empathizing, systemizing, and the extreme male brain theory of autism. Progress in Brain Research, 186, 167175. HTTPS://DOI.ORG/10.1016/B978-0-444-536303.00011-7

Baron-Cohen, Simon y Hammer, J. (1997). Is autism an extreme form of the "male brain»? Advances in Infancy Research, 11, 193-217.

Baron-Cohen, Simon, Lombardo, M. V., Auyeung, B., Ashwin, E., Chakrabarti, B. y Knickmeyer, R. (2011). Why are autism spectrum conditions more prevalent in males? PLoS Biology, 9(6), e1001081. HTTPS://DOI.ORG/10.1371/JOURNAL. PBIO.1001081

Barttfeld, P., Amoruso, L., Ais, J., Cukier, S. Bavassi, L., Tomio, A., ... Sigman, M. (2013). Organization of brain networks governed by long-range connections index autistic traits in the general population. Journal of Neurodevelopmental Disorders, 5(1), 16. нттрs:// DOI.ORG/10.1186/1866-1955-5-16

Bauman, M. L. y Kemper, T. L. (2005). The neurobiology of autism (2. ${ }^{\mathrm{a}}$ ed.). Baltimore: Johns Hopkins University Press.

Betancur, C. (2011). Etiological heterogeneity in autism spectrum disorders: More than 100 genetic and genomic disorders and still counting. Brain Research, 1380, 42-77. HTTPS://DOI. ORG/10.1016/J.BRAINRES.2010.11.078

Blanken, L. M. E., Mous, S. E., Ghassabian, A., Muetzel, R. L., Schoemaker, N. K., El Marroun, H., ... White, T. (2015). Cortical morphology in 6- to 10-year old children with autistic traits: A population-based neuroimaging study. American Journal of Psychiatry, 172(5), 479-486. HTTPS:// DOI.ORG/10.1176/APPI.AJP.2014.14040482

Brothers, L. (2002). The social brain: a project for integrating primate behavior and neurophysiology in a new domain. En J. T. Cacioppo, G. G. Berntson, R. Adolphs, C. S. Carter, R. J. Davidson, M. McClintock, ... S. E. Taylor (Eds.), Foundations in social neuroscience (pp. 367-385). Cambridge: The MIT Press.

Cabrera, D. (2007). Generalities about autism. Revista Colombiana de Psiquiatría, 36(1), 208220. 
Cadaveira, M. y Waisburg, C. (2014). Autismo: guía para padres y profesionales. Ciudad Autónoma de Buenos Aires: Paidós.

Carper, R. A., Treiber, J. M., White, N. S., Kohli, J. S. y Müller, R.-A. (2017). Restriction spectrum imaging as a potential measure of cortical neurite density in autism. Frontiers in Neuroscience, 10, 610. HTTPS://DOI.ORG/10.3389/FNINS.2016.00610

CDC - Centers for Disease Control and Prevention (2014). Autism Spectrum Disorder (ASD). Data \& statistics. Recuperado a partir de нттр://WwW. CDC.GOV/NCBDDD/AUTISM/DATA.HTML

Chen, J. A., Peñagarikano, O., Belgard, T. G., Swarup, V. y Geschwind, D. H. (2015). The emerging picture of Autism Spectrum Disorder: Genetics and pathology. Annual Review of Pathology: Mechanisms of Disease, 10(1), 111144. HTTPS://DOI.ORG/10.1146/ANNUREVPATHOL-012414-040405

Clipperton-Allen, A. E., Chen, Y. y Page, D. T (2016). Autism-relevant behaviors are minimally impacted by conditional deletion of Pten in oxytocinergic neurons: Conditional deletion of Pten in Oxt cells. Autism Research, 9(12), 12481262. HTTPS://DOI.ORG/10.1002/AUR.1641

Courchesne, E., Carper, R. y Akshoomoff, N. (2003). Evidence of brain overgrowth in the first year of life in autism. Journal of the American Medical Association, 290(3), 337-344. HTTPs://DOI. ORG/10.1001/JAMA.290.3.337

Cukier, S. H. (2005). Aspectos clínicos, biológicos y neuropsicológicos del trastorno autista: hacia una perspectiva integradora. Revista Argentina de Psiquiatría, 16(62), 273-278.

De la Torre-Ubieta, L., Won, H., Stein, J. L. y Geschwind, D. H. (2016). Advancing the understanding of autism disease mechanisms through genetics. Nature Medicine, 22(4), $345-$ 361. HTTPS://DOI.ORG/10.1038/NM.4071

Di Martino, A., Yan, C.-G., Li, Q., Denio, E. Castellanos, F. X., Alaerts, K., ... Milham, M. P. (2014). The autism brain imaging data exchange: towards a large-scale evaluation of the intrinsic brain architecture in autism. Molecular Psychiatry, 19(6), 659-667. HтTPs:// DOI.ORG/10.1038/MP.2013.78

DiCicco-Bloom, E., Lord, C., Zwaigenbaum, L. Courchesne, E., Dager, S. R., Schmitz, C., ... Young, L. J. (2006). The developmental neurobiology of Autism Spectrum Disorder. Journal of Neuroscience, 26(26), 6897-6906. HTTPS://DOI. ORG/10.1523/JNEUROSCI.1712-06.2006
Domes, G., Heinrichs, M., Kumbier, E., Grossmann, A., Hauenstein, K. y Herpertz, S. C. (2013). Effects of intranasal oxytocin on the neural basis of face processing in Autism Spectrum Disorder. Biological Psychiatry, 74(3), 164-171. HTTPs://DOI. ORG/10.1016/J.BIOPSYCH.2013.02.007

Dunbar, R. I. (1998). The social brain hypothesis. Brain, 9(10), 178-190. HTTPS://DOI.ORG/10.1002/ (SICI)1520-6505

Escera, C. (2004). Aproximación histórica y conceptual a la neurociencia cognitiva. Cognitiva, 16(2), 141-161. HTTPs://DOI. ORG/10.1174/0214355042248929

Espín Jaime, J. C., Cerezo Navarro, M. V. y Espín Jaime, F. (2013). Lo que es Trastorno del Espectro Autista y lo que no lo es. Anales de Pediatría Continuada, 11(6), 333-341.

Fariña, L., Galli, E., Lazo, M., Mattei, L. y Raggio, V. (2015). Genética molecular y trastornos del espectro autista. Anales de la Facultad de Medicina, 2, 9-21.

Folstein, S. y Rutter, M. (1977). Genetic influences and infantile autism. Nature, 265(5596), 726-728. HTTPS://DOI.ORG/10.1038/265726AO

Fuccillo, M. V. (2016). Striatal circuits as a common node for autism pathophysiology. Frontiers in Neuroscience, 10. HTTPS://DOI.ORG/10.3389/ FNINS.2016.00027

Garcés-Vieira, M. V. y Suárez-Escudero, J. C. (2012). Neuroplasticidad: aspectos bioquímicos y neurofisiológicos. Revista CES Medicina, 28(1), 119-132.

García, R., Ayala, P. A. y Perdomo, S. P. (2012). Epigenética: definición, bases moleculares e implicaciones en la salud y en la evolución humana. Revista Ciencias de la Salud, 10(1), 5971.

Gazzaniga, M. S. (2009). The cognitive neurosciences. Cambridge: The MIT Press.

Geschwind, D. H. y State, M. W. (2015). Gene hunting in Autism Spectrum Disorder: on the path to precision medicine. The Lancet Neurology, 14(11), 1109-1120. HTTPS://DOI.ORG/10.1016/ S1474-4422(15)00044-7

González, B. P. y Menchaca, N. F. (2007). Neurobiología del autismo: estudio de neuropatología y neuroimagen. Actas Españolas de Psiquiatría, 35(4). 
Gordon, I., Vander Wyk, B. C., Bennett, R. H., Cordeaux, C., Lucas, M. V., Eilbott, J. A., ... Pelphrey, K. A. (2013). Oxytocin enhances brain function in children with autism. Proceedings of the National Academy of Sciences, 110(52), 20953-20958. HTTPS://DOI.ORG/10.1073/

PNAS. 1312857110

Hazlett, H. C., Poe, M. D., Gerig, G., Styner, M., Chappell, C., Smith, R. G., ... Piven, J. (2011). Early brain overgrowth in autism associated with an increase in cortical surface area before age 2 years. Archives of General Psychiatry, 68(5), 467. HTTPs://DOI.ORG/10.1001/ ARCHGENPSYCHIATRY.2011.39

Heinrichs, M. y Domes, G. (2008). Neuropeptides and social behaviour: effects of oxytocin and vasopressin in humans. Progress in Brain Research, 170, 337-350. HTTPs://DOI.ORG/10.1016/ soo79-6123(08)00428-7

Herbert, M. R., Ziegler, D. A., Deutsch, C. K., O’Brien, L. M., Lange, N., Bakardjiev, A., ... Caviness, V. S. (2003a). Dissociations of cerebral cortex, subcortical and cerebral white matter volumes in autistic boys. Brain, 126(5), 1182-1192. HTTPS://DOI.ORG/10.1093/BRAIN/AWG110

Herbert, M. R., Ziegler, D. A., Makris, N., Bakardjiev, A., Hodgson, J., Adrien, K. T., ... Caviness, V. S. (2003b). Larger brain and white matter volumes in children with developmental language disorder. Developmental Science, 6(4), F11-F22. HTTPS://DOI.ORG/10.1111/1467-7687.00291

Herbert, M. R., Ziegler, D. A., Makris, N., Filipek, P. A., Kemper, T. L., Normandin, J. J., ... Caviness, V. S. (2004). Localization of white matter volume increase in autism and developmental language disorder. Annals of Neurology, 55(4), 530-540. HTTPS://DOI.ORG/10.1002/ANA.20032

Herpertz, S. C. y Bertsch, K. (2014). The socialcognitive basis of personality disorders. Current Opinion in Psychiatry, 27(1), 73-77. HTTPS://DOI. ORG/10.1097/YCO.0000000000000026

Hollander, E., Bartz, J., Chaplin, W., Phillips, A., Sumner, J., Soorya, L., ... Wasserman, S. (2007). Oxytocin Increases retention of social cognition in autism. Biological Psychiatry, 61(4), 498-503. HTTPS://DOI.ORG/10.1016/J.BIOPSYCH.2006.05.030

Hollander, E., Novotny, S., Hanratty, M., Yaffe, R. DeCaria, C. M., Aronowitz, B. R. y Mosovich, S. (2003). Oxytocin infusion reduces repetitive behaviors in adults with autistic and Asperger's disorders. Neuropsychopharmacology, 28(1), 193 198. HTTPS://DOI.ORG/10.1038/sJ.NPP.1300021

Hulbert, S. W. y Jiang, Y. (2017). Cellular and circuitry bases of autism: Lessons learned from the temporospatial manipulation of autism genes in the brain. Neuroscience Bulletin, 33(2), 205218. HTTPS://DOI.ORG/10.1007/S12264-017-0112-7

Hulbert, S.W. y Jiang, Y.-H. (2016). Monogenic mouse models of autism spectrum disorders: Common mechanisms and missing links. Neuroscience, 321, 3-23. HTTPS://DOI.ORG/10.1016/J. NEUROSCIENCE.2015.12.040

Hutsler, J. J. y Casanova, M. F. (2016). Cortical construction in autism spectrum disorder: Columns, connectivity and the subplate. Neuropathology and Applied Neurobiology, 42(2), 115-134. HTTPS://DOI.ORG/10.1111/NAN.12227

IsHak, W. W., Kahloon, M. y Fakhry, H. (2011). Oxytocin role in enhancing well-being: A literature review. Journal of Affective Disorders, 130(1-2), 1-9. HTTPS://DOI.ORG/10.1016/J. JAD.2010.06.001

Jiao, Y., Chen, R., Ke, X., Chu, K., Lu, Z. y Herskovits, E.H. (2010). Predictive models of autism spectrum disorder based on brain regional cortical thickness. NeuroImage, 50(2), 589-599. нтTPs:// DOI.ORG/10.1016/J.NEUROIMAGE.2009.12.047

Juvenal, G. J. (2014). Epigenética: vieja palabra, nuevos conceptos. Revista Argentina de Endocrinología y Metabolismo, 51(2), 66-74.

Kanner, L. (1943/1993). Autistic disturbances of affective contact. Nervous Child, 2, 217250.

Kaulino, A. y Stecher, A. (Eds.). (2008). Cartografía de la psicología contemporánea. Pluralismo y modernidad. Santiago de Chile: LOM Ediciones.

Kays, J. L., Hurley, R. A. y Taber, K. H. (2012). The dynamic brain: neuroplasticity and mental health. The Journal of Neuropsychiatry and Clinical Neurosciences, 24(1), 118-124. нтTPs:// DOI.ORG/10.1176/APPI.NEUROPSYCH.24.1.118

Lai, M.-C., Lombardo, M. V., Auyeung, B., Chakrabarti, B. y Baron-Cohen, S. (2015). Sex/ gender differences and autism: Setting the scene for future research. Journal of the American Academy of Child \& Adolescent Psychiatry, 54(1), 11-24. HTTPS://DOI.ORG/10.1016/J. JAAC. 2014.10.003

Lai, M.-C., Lombardo, M. V. y Baron-Cohen, S. (2014). Autism. The Lancet, 383(9920), 896-910. HTTPS://DOI.ORG/10.1016/s0140-6736(13)61539-1

Lai, M.-C., Lombardo, M. V., Ecker, C., Chakrabarti, B., Suckling, J., Bullmore, E. T., ... Baron-Cohen, S. (2015). Neuroanatomy of individual differences in language in adult males with autism. Cerebral Cortex, 25(10), 3613-3628. HTTPS://DOI. ORG/10.1093/CERCOR/BHU211 
Leone, A. P. (2009). Characterizing and modulating neuroplasticity of the adult human brain. En M. S. Gazzaniga (Ed.), The cognitive neurosciences (pp. 141-152). Cambridge: The MIT Press.

Levitt, P. y Campbell, D. B. (2009). The genetic and neurobiologic compass points toward common signaling dysfunctions in autism spectrum disorders. Journal of Clinical Investigation, 119(4), 747-754. HTTPS://DOI.ORG/10.1172/JCI37934

Liu, Z., Li, X., Zhang, J.-T., Cai, Y.-J., Cheng, T.L., Cheng, C., ... Qiu, Z. (2016). Autism-like behaviours and germline transmission in transgenic monkeys overexpressing MeCP2. Nature, $\quad 530(7588), \quad 98-102 . \quad$ HтTPs://DoI. ORG/10.1038/NATURE16533

Lombardi, L. M., Baker, S. A. y Zoghbi, H. Y. (2015). MECP2 disorders: from the clinic to mice and back. Journal of Clinical Investigation, 125(8), 2914-2923. HTTPS://DOI.ORG/10.1172/JCI78167

LoParo, D. y Waldman, I. D. (2015). The oxytocin receptor gene (OXTR) is associated with autism spectrum disorder: a meta-analysis. Molecular Psychiatry, 20(5), 640-646. HтTPs://DoI. ORG/10.1038/MP.2014.77

Lord, C., Rutter, M. y Le Couteur, A. (1994). Autism diagnostic interview-revised: A revised version of a diagnostic interview for caregivers of individuals with possible pervasive developmental disorders. Journal of Autism and Developmental Disorders, 24(5), 659-685. HTTPS://DOI.ORG/10.1007/ BF02172145

Maia, L. A. C. R., Da Silva, C. R., Correia, C. R. y Bartolomé, M. V. P. (2006). El modelo de Alexander Romanovich Luria (revisitado) y su aplicación a la evaluación neuropsicológica. Revista Galego-Portuguesa de Psicoloxía e Educación, 11(13), 155-194.

Mannion, A. y Leader, G. (2013). Comorbidity in autism spectrum disorder: A literature review. Research in Autism Spectrum Disorders, 7(12), 1595-1616. HTTPS://DOI.ORG/10.1016/J. RASD. 2013.09.006

Martins, G. J. (2017). Neurobiology of autism spectrum disorders. En B. Barahona Correa y R. J. van der Gaag (Eds.), Autism spectrum disorders in adults (pp. 29-93). Lisboa: Springer International Publishing.

Meltzer, A. y Van de Water, J. (2017). The role of the immune system in Autism Spectrum Disorder. Neuropsychopharmacology, 42(1), 284-298. HTTPS://DOI.ORG/10.1038/NPP.2016.158
Miles, J. H. (2011). Autism spectrum disorders-A genetics review. Genetics in Medicine, 13(4), 278-294. HTTPS://DOI.ORG/10.1097/ GIM.0B013Е3181FF67BA

Minshew, N. J. y Payton, J. B. (1988). New perspectives in autism. Part 2: the differential diagnosis and neurobiology of autism. Current Problems in Pediatrics, 18(11), 618-694. нттрs:// DOI.ORG/10.1016/0045-9380(88)90017-5

Minshew, N. J., Sweeney, J. A., Bauman, M. L. y Webb, S. J. (2013). Neurologic aspects of autism. En F. R. Volkmar, R. Paul, A. Klin, y D. Cohen (Eds.), Handbook of Autism and Pervasive Developmental Disorders (pp. 473-514). Hoboken: John Wiley \& Sons, Inc. HTtPs://DoI. ORG/10.1002/9780470939345.CH18

Minshew, N. J. y Williams, D. L. (2007). The new neurobiology of autism: Cortex, connectivity, and neuronal organization. Archives of Neurology, 64(7), 945. HTTPS://DOI.ORG/10.1001/ ARCHNEUR.64.7.945

Morant, A., Mulas, F. y Hernández, S. (2001). Bases neurobiológicas del autismo. Neurología Clínica, 2(1), 163-171.

Mulas, F., Etchepareborda, M. C., Hernández, S., Abad, L., Téllez de Meneses, M. y Mattos, L. (2005). Bases neurobiológicas de los trastornos específicos de la comunicación (espectro autista). Neurología, 41(1), S149-S153.

Mullins, C., Fishell, G. y Tsien, R. W. (2016). Unifying views of Autism Spectrum Disorders: A consideration of autoregulatory feedback loops. Neuron, 89(6), 1131-1156. HTTPs://DOI. ORG/10.1016/J.NEURON.2016.02.017

Nevile, H. y Sur, M. (2009). Introduction. En M. S. Gazzaniga (Ed.), The cognitive neurosciences (p. 89). Cambridge: The MIT Press.

Palau-Baduell, M., Salvadó-Salvadó, B., ClofentTorrentó, M. y Valls-Santasusana, A. (2012). Autismo y conectividad neural. Revista de Neurología, 54(1), S31-S39.

Pelphrey, K. A., Shultz, S., Hudac, C. M. y Vander Wyk, B. C. (2011). Constraining heterogeneity: the social brain and its development in autism spectrum disorder. Journal of Child Psychology and Psychiatry, 52(6), 631-644. HTTPs://DOI. ORG/10.1111/J.1469-7610.2010.02349.X

Piro, M. C. (2015). Las variedades del autismo: su presentación en la demanda asistencial. Temas en Psicología, 2, 13-32. 
Pobbe, R. L. H., Pearson, B. L., Defensor, E. B., Bolivar, V. J., Young, W. S., Lee, H.-J., ... Blanchard, R. J. (2012). Oxytocin receptor knockout mice display deficits in the expression of autismrelated behaviors. Hormones and Behavior, 61(3), 436-444. HTTPS://DOI.ORG/10.1016/J. YHBEH.2011.10.010

Rapin, I. y Katzman, R. (1998). Neurobiology of autism. Annals of Neurology, 43(1), 7-14. HтTPs:// DOI.ORG/10.1002/ANA.410430106

Rivière, Á. (2001). Autismo. Orientaciones para la intervención educativa. Madrid: Trotta.

Rotta, N. T. (2013). Trastorno del espectro autista y trastorno específico del lenguaje ¿dos entidades diferentes o un continuo de manifestaciones neuropsicológicas? Medicina, 73(1), 10-15.

Schaer, M., Kochalka, J., Padmanabhan, A., Supekar K. y Menon, V. (2015). Sex differences in cortical volume and gyrification in autism. Molecular Autism, 6(1). HTTPs://DOI.ORG/10.1186/s13229015-0035-Y

Shou, X.-J., Xu, X.-J., Zeng, X.-Z., Liu, Y., Yuan, H.S., Xing, Y., ... Han, J.-S. (2017). A volumetric and functional connectivity MRI study of brain arginine-vasopressin pathways in autistic children. Neuroscience Bulletin, 33(2), 130-142. HTTPS://DOI.ORG/10.1007/S12264-017-0109-2

Sierra-Fitzgerald, O. y Munévar, G. (2007). Nuevas ventanas hacia el cerebro humano y su impacto en la neurociencia cognoscitiva. Revista Latinoamericana de Psicología, 39(1), 143-157. HTTPS://DOI.ORG/10.14349/RLP.V39I1.625

Sztainberg, Y., Chen, H., Swann, J. W., Hao, S., Tang, B., Wu, Z., ... Zoghbi, H. Y. (2015). Reversal of phenotypes in MECP2 duplication mice using genetic rescue or antisense oligonucleotides. Nature, 528(7580), 123-126. HTTPS://DOI. ORG/10.1038/NATURE16159

Sztainberg, Y. y Zoghbi, H. Y. (2016). Lessons learned from studying syndromic autism spectrum disorders. Nature Neuroscience, 19(11), 14081417. HTTPS://DOI.ORG/10.1038/NN.4420

Tick, B., Bolton, P., Happé, F., Rutter, M. y Rijsdijk, F. (2016). Heritability of autism spectrum disorders: a meta-analysis of twin studies. Journal of Child Psychology and Psychiatry, 57(5), 585-595. HTTPS://DOI.ORG/10.1111/JCPP.12499
Urrútia, G. y Bonfill, X. (2010). Declaración PRISMA: una propuesta para mejorar la publicación de revisiones sistemáticas y metaanálisis. Medicina Clínica, 135(11), 507-511. HTTPs://DOI. ORG/10.1016/J.MEDCLI.2010.01.015

Wang, M., Li, H., Takumi, T., Qiu, Z., Xu, X., Yu, X. y Bian, W.-J. (2017). Distinct defects in spine formation or pruning in two gene duplication mouse models of autism. Neuroscience Bulletin, 33(2), 143-152. HTTPS://DOI.ORG/10.1007/S12264017-0111-8

Werling, D. M. (2016). The role of sex-differential biology in risk for autism spectrum disorder. Biology of Sex Differences, 7(1), 58. HTTPS://DOI. ORG/10.1186/s13293-016-0112-8

Wolff, J. J., Gu, H., Gerig, G., Elison, J. T., Styner, M., Gouttard, S., ... the IBIS Network. (2012). Differences in white matter fiber tract development present from 6 to 24 months in infants with autism. American Journal of Psychiatry, 169(6), 589-600. HTTPS://DOI. ORG/10.1176/APPI.AJP.2011.11091447

Wu, S., Jia, M., Ruan, Y., Liu, J., Guo, Y., Shuang, M., ... Zhang, D. (2005). Positive association of the oxytocin receptor gene (OXTR) with autism in the chinese Han population. Biological Psychiatry, 58(1), 74-77. HTTPS://DOI. ORG/10.1016/J.BIOPSYCH.2005.03.013

Xu, X., Miller, E. C. y Pozzo-Miller, L. (2014). Dendritic spine dysgenesis in Rett syndrome. Frontiers in Neuroanatomy, 8(97), 1-8. нттPs:// DOI.ORG/10.3389/FNANA.2014.00 097

Young, L. J. y Barrett, C. E. (2015). Can oxytocin treat autism? Science, 347(6224), 825-826. HTTPS://DOI. ORG/10.1126/SCIENCE.AAA8120

Zhang, R., Zhang, H.-F., Han, J.-S. y Han, S.-P. (2017). Genes related to oxytocin and argininevasopressin pathways: Associations with Autism Spectrum Disorders. Neuroscience Bulletin, 33(2), 238-246. HTTPS://DOI.ORG/10.1007/s12264-0170120-7 